The authors have retracted Whigham et al. after discovering a confounding effect of the titer of the bacterium used that had not been controlled for, rendering some of the experimental results presented in the paper inconclusive. This article was retracted on 24 May 2018.

\title{
Broadly Conserved Fungal Effector BEC1019 Suppresses Host Cell Death and Enhances Pathogen Virulence in Powdery Mildew of Barley (Hordeum vulgare L.)
}

\author{
Ehren Whigham, ${ }^{1}$ Shan $\mathrm{Qi},{ }^{2}$ Divya Mistry, ${ }^{3}$ Priyanka Surana, ${ }^{1,3}$ Ruo Xu, ${ }^{4}$ Gregory Fuerst, ${ }^{1,5}$ \\ Clara Pliego, ${ }^{6}$ Laurence V. Bindschedler, ${ }^{7}$ Pietro D. Spanu, ${ }^{6}$ Julie A. Dickerson, ${ }^{3,8}$ Roger W. Innes, ${ }^{9}$ \\ Dan Nettleton, ${ }^{4}$ Adam J. Bogdanove, ${ }^{2}$ and Roger P. Wise ${ }^{1,3,5}$ \\ ${ }^{1}$ Department of Plant Pathology and Microbiology, lowa State University, Ames, lowa, 50011, U.S.A.; ${ }^{2}$ Plant Pathology and \\ Plant-Microbe Biology Section, School of Integrative Plant Science, Cornell University, Ithaca, New York, 14853, U.S.A.; \\ ${ }^{3}$ Bioinformatics and Computational Biology, lowa State University; ${ }^{4}$ Department of Statistics, lowa State University; ${ }^{5}$ Corn \\ Insects and Crop Genetics Research, USDA-Agricultural Research Service, lowa State University; ${ }^{6}$ Department of Life \\ Sciences, Imperial College London, South Kensington Campus, London SW7 2AZ, U. K.; ${ }^{7}$ School of Biological Sciences, Royal \\ Holloway University of London (RHUL), Egham, Surrey, TW20 0EX, U. K.; ${ }^{8}$ Department of Electrical and Computer Engineering, \\ lowa State University; ${ }^{9}$ Department of Biology, Indiana University, Bloomington, IN, 47405, U.S.A.
}

Submitted 9 February 2015. Accepted 30 April 2015. Retracted 24 May 2018.

The interaction of barley, Hordeum vulgare L., with the powdery mildew fungus Blumeria graminis f. sp. hordei is a well-developed model to investigate resistance and susceptibility to obligate biotrophic pathogens. The 130-Mb Blumeria genome encodes approximately 540 predicted effectors that are hypothesized to suppress or induce host processes to promote colonization. Blumeria effector candidate $(B E C) 1019$, a single-copy gene encoding a putative, secreted metalloprotease, is expressed in haustorial feeding structures, and host-induced gene silencing of BEC101y restricts haustorial development in compatible interactions. Here, we show that Barley stripe mosaic virus-induced gene silencing of $B E C 1019$ significantly reduces fungal colonization of barley epidermal cells, demonstrating that BEC1019 plays a central role in virulence. In addition, delivery of BEC1019 to the host cytoplasm via Xanthomonas type III secretion suppresses cultivar nonspecific hypersensitive reaction (HR) induced by Xanthomonas

Mention of trade names or commercial products in this publication is solely for the purpose of providing specific information and does not imply recommendation or endorsement by either the U.S. Department of Agriculture or the National Science Foundation.

For distribution of type III secretion materials, contact Adam J. Bogdanove: ajb7@cornell.edu

Current address for E. Whigham: Roosevelt High School, 4419 Center Street, Des Moines, IA, 50312, U.S.A.

Current address for R. Xu: Google Inc., 1600 Amphitheatre Pkwy, Mountain View, CA, 94043, U.S.A.

Current address for C. Pliego: Instituto Andaluz de Investigación y Formación Agraria y Pesquera, IFAPA-Centro de Churriana, Cortijo de la Cruz s/n, 29140 Málaga, Spain

Corresponding author: Roger P. Wise; roger.wise@ars.usda.gov

*The $\boldsymbol{e}$-Xtra logo stands for "electronic extra" and indicates that eight supplementary figures and four supplementary tables are published online.

This article is in the public domain and not copyrightable. It may be freely reprinted with customary crediting of the source. The American Phytopathological Society, 2015 oryzae pv. oryzicola, as well as cultivar-specific HR induced by AvrPphB from Pseudomonas syringae pv. phaseolicola. BEC1019 homologs are present in 96 of 241 sequenced fungal genomes, including plant pathogens, human pathogens, and free-living nonpathogens. Comparative analysis revealed variation at several amino acid positions that correlate with fungal lifestyle and several highly conserved, noncorrelated motifs. Site-directed mutagenesis of one of these, ETVIC, compromises the HR-suppressing activity of BEC1019. We postulate that BEC1019 represents an ancient, broadly important fungal protein family, members of which have evolved to function as effectors in plant and animal hosts.

Obligate fungal pathogens, i.e., pathogens that require their host to survive, are a major threat to crop production worldwide. Effector proteins secreted by these pathogens inhibit or accelerate host processes to co-opt the host cellular environment for nutrient acquisition and colonization. The interaction of barley, Hordeum vulgare L., with the powdery mildew fungus Blumeria graminis f. sp. hordei is an ideal model to explore the molecular mechanisms by which effectors manipulate these processes. After a conidiospore lands on the leaf surface, an appressorium develops, from which a hyphal peg penetrates the cuticle and the epidermal cell wall. Here, the pathogen forms its feeding structure, the haustorium, surrounded by a perihaustorial membrane that is continuous with but distinct from the plasma membrane of the epidermal cell (Dörmann et al. 2014). Using nutrients obtained from the host, secondary hyphae on the leaf surface infect additional epidermal cells. Infection of epidermal cells by $B$. graminis is hypothesized to involve delivery of secreted effectors into the host to suppress defense. Genomic and proteomic studies have identified about 540 Blumeria effector candidates (BEC) or candidate secreted effector proteins (CSEP) (Bindschedler et al. 2011; Kusch et al. 2014; Pedersen et al. 2012; Spanu et al. 2010). A small number of these have been characterized (Ahmed et al. 2015; Pliego et al. 2013; Schmidt et al. 2014; Zhang et al. 2012), but the molecular mechanisms by which effectors manipulate host processes to promote colonization are still poorly understood.

The plant defense response includes two interdependent pathways, pathogen-associated molecular pattern (PAMP)-triggered 
immunity and effector-triggered immunity (ETI) (Bent and Mackey 2007; Macho and Zipfel 2014). PAMPs are recognized by host transmembrane recognition receptors that then signal, at least in part, through a downstream mitogen-activated protein kinase cascade (Boller and Felix 2009; Boller and He 2009). ETI is mediated by host resistance $(R)$ genes, which often encode cytoplasmic nucleotide binding-leucine rich repeat (NLR) proteins (Bent and Mackey 2007; Cesari et al. 2014; Jacob et al. 2013). The direct or indirect interaction between an effector and an NLR protein results in resistance, usually associated with a hypersensitive reaction (HR), defined in this study as a rapid cell death at the infection site. In order to survive, pathogens have evolved or acquired effectors that suppress these defense responses (Boller and Felix 2009; Boller and He 2009; Kjemtrup et al. 2000; Stergiopoulos and de Wit 2009).

We previously screened 50 selected $B E C$ genes by hostinduced gene silencing (HIGS) (Nowara et al. 2010) and found eight that are important for haustorial development (Pliego et al. 2013). Some of these genes encode proteins unique to powdery mildews, while others show varying degrees of conservation across fungal taxa. Characterization of effectors exclusive to the mildews has the potential to shed light on the nature of obligate biotrophy. Alternatively, effectors that are broadly conserved may reveal plant defense gene targets that could be exploited to engineer resistance to a spectrum of fungal pathogens. The focus of this study is BEC1019 (GenBank KJ571201) (Bindschedler et al. 2011), which is conserved across a broad range of fungal taxa. We found that Barley stripe mosaic virus-induced gene silencing (BSMV-VIGS) of BEC1019 significantly reduced the accumulation of fungal hyphae on the surface of barley leaves, revealing a central role for BEC1019 in virulence and colonization. In addition, Xanthomonas type III secretion (T3S)-based delivery of BEC1019 suppressed both cultivar-nonspecific HR induced by Xanthomonas oryzae pv. oryzicola and cultivar-specific HR in duced by the AvrPphB effector from Pseudomonas syringae pv. phaseolicola (Ade et al. 2007; DeYoung et al. 2012; Shao et al. 2003). Moreover, homologs of BEC1019 are conserved in more than 90 fungal taxa. Site-directed mutagenesis of BEC1019 revealed a conserved ETVIC motif to be required for suppression of $\mathrm{HR}$. We conclude that this widely distributed protein has evolved to play a key role in the survival and reproduction of the obligate biotrophic fungus $B$. graminis by suppressing host defense.

\section{RESULTS}

BSMV-VIGS of BEC1019 impedes fungal growth in incompatible interaction.

Silencing B. graminis effectors should alter the ability of the fungus to infect and colonize barley. Indeed, when BEC1019 is subjected to single cell HIGS (Nowara et al. 2010), B. graminis develops significantly fewer haustoria compared with a control interaction (Pliego et al. 2013). To extend these single-cell results to whole leaves, we adopted our bombardment-based BSMVVIGS system, a systemic transient gene-silencing assay that enables quantification of fungal growth (Meng and Wise 2012; Meng et al. 2009). A 264-nucleotide region from the middle of the BEC1019 coding sequence was inserted into the BSMV: $\gamma$ genome to create the silencing construct, designated BSMV: 1019368-632. The wild-type BSMV: $\gamma$ was used as a negative control, designated BSMV:00. First leaves from 7-day-old barley cv. HOR11358 (Mla9) plants were mechanically inoculated with sap from leaves previously bombarded with these constructs (discussed below), and after 12 days, plants that displayed BSMV symptoms were inoculated with the compatible $B$. graminis $\mathrm{f}$. sp. hordei isolate $5874\left(a v r_{a 9}\right)$. Seven days later, third leaves were assessed for fungal growth and were imaged (Fig. 1A). The experiment was conducted in four independent biological replications of eight to ten plants per treatment, resulting in a total of 32 individual leaves scored per treatment.

To quantify hyphal growth on the surface of epidermal cells, we developed a MATLAB image processing software program, designated LeafQuant-VIGS (discussed in Materials and Methods). Starting with high-resolution RGB images of each leaf, LeafQuant first defines the edges, then detects the background and converts it to uniformly true black, and subsequently, converts the high-resolution color RGB image to an 8-bit grayscale image with 256 shades of gray (Fig. 1B). Because elongating secondary hyphae, an indicator of functional haustoria (Ellingboe 1972), are white and the barley leaf is green, these contrasts can be used to quantify fungal growth.

Treatment with the VIGS construct BSMV:1019 ${ }_{368-632}$ resulted in significantly less fungal growth compared with BSMV:00 and mock treatments (Fig. 1A and B). We tested if silencing of $B E C 1019$ was correlated to this reduced fungal growth by plotting real-time quantitative reverse transcription-polymerase chain reaction (qRT-PCR) $\log _{2}$ relative expression levels from the 32 individual leaves treated with BSMV:1019368-632 against the percent infection output from LeafQuant-VIGS for those leaves (Fig. 1D). We then conducted four linear mixed model analyses (discussed below), showing that, whenever BEC1019 was successfully silenced, there was less hyphal growth on epidermal cells $(P=0.0019)$ (Fig. 1B and D), indicating an essential role for BEC1019 in the ability of the pathogen to colonize its host.

As an independent measure of fungal growth, we also carried out qRT-PCR for four B. graminis transcripts that are not significantly differentially expressed during development, based on surveys of publicly available RNA-Seq data (Hacquard et al. 2013) and two others that represent alternative isoforms encoding chitin, a fungal cell-wall component (Ayliffe et al. 2013). For this experiment, we used RNA from the third leaf of three BSMV: 1019-silenced plants and three BSMV:00-treated plants that showed low and high amounts, respectively, of fungal growth, as determined by LeafQuant-VIGS. Each of the six transcripts was less abundant in the (BEC1019-silenced) leaves with low amounts of fungal growth than in the (BSMV:00 treated) leaves with high amounts of fungal growth (Fig. 1E; Supplementary Table S4), corroborating the LeafQuant-VIGS results.

\section{BEC1019 suppresses barley HR caused}

by $X$. oryzae pv. oryzicola BLS256.

We expect that bona fide effectors should be able to induce or suppress HR in barley. Assaying individual B. graminis effectors has been difficult, due to the obligate biotrophic nature of this pathogen and the lack of a robust transformation protocol (Pliego et al. 2013). To overcome these obstacles, we adapted the bacterial T3S system to deliver heterologous effector candidates into barley cells. Pseudomonas spp. have been used as a delivery vehicle in Arabidopsis thaliana to characterize oomycete effector proteins by fusion to the type III signals of avirulence proteins AvrRps4 and AvrRpm1 (Rentel et al. 2008; Sohn et al. 2007); this system was also recently used in wheat to investigate effector candidates from the stem rust fungus Puccinia graminis tritici (Upadhyaya et al. 2014). Additionally, Sharma and colleagues (2013) have employed the Burkholderia glumae T3S system to transfer Magnaporthe oryzae effectors to rice cells.

For our purposes, we selected $X$. campestris pv. raphani 756C (Kamoun et al. 1992), which causes bacterial spot of brassicas, and $X$. oryzae pv. oryzicola BLS256, which causes bacterial leaf streak of rice. When syringe-infiltrated into barley leaves, strain $756 \mathrm{C}$ elicits no visible response, while strain BLS256 elicits an HR. Therefore, these bacterial strains offer the opportunity, individually or in combination, to screen for HReliciting or HR-suppressing effectors. In searching for HR suppressors, coinfiltration of strain $756 \mathrm{C}$ delivering a test effector 


\section{C}

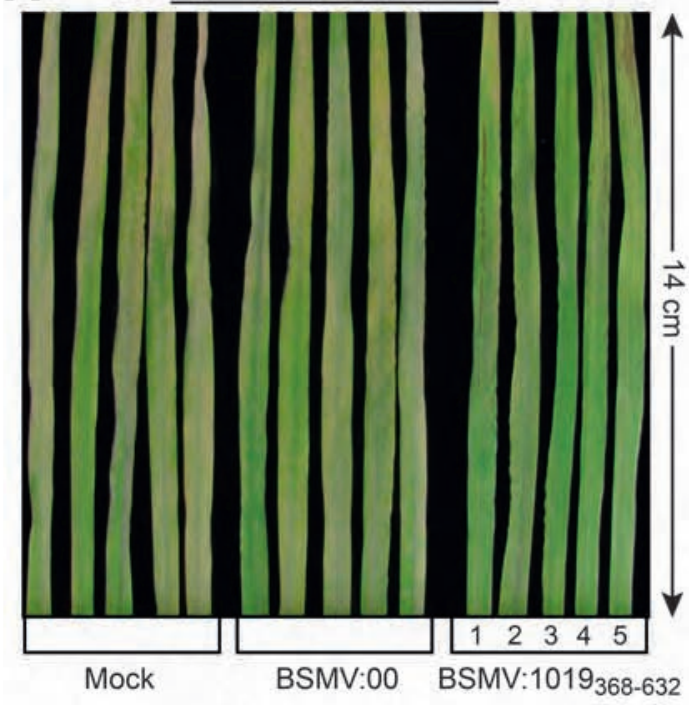

B Percent Infection (LQ Output)
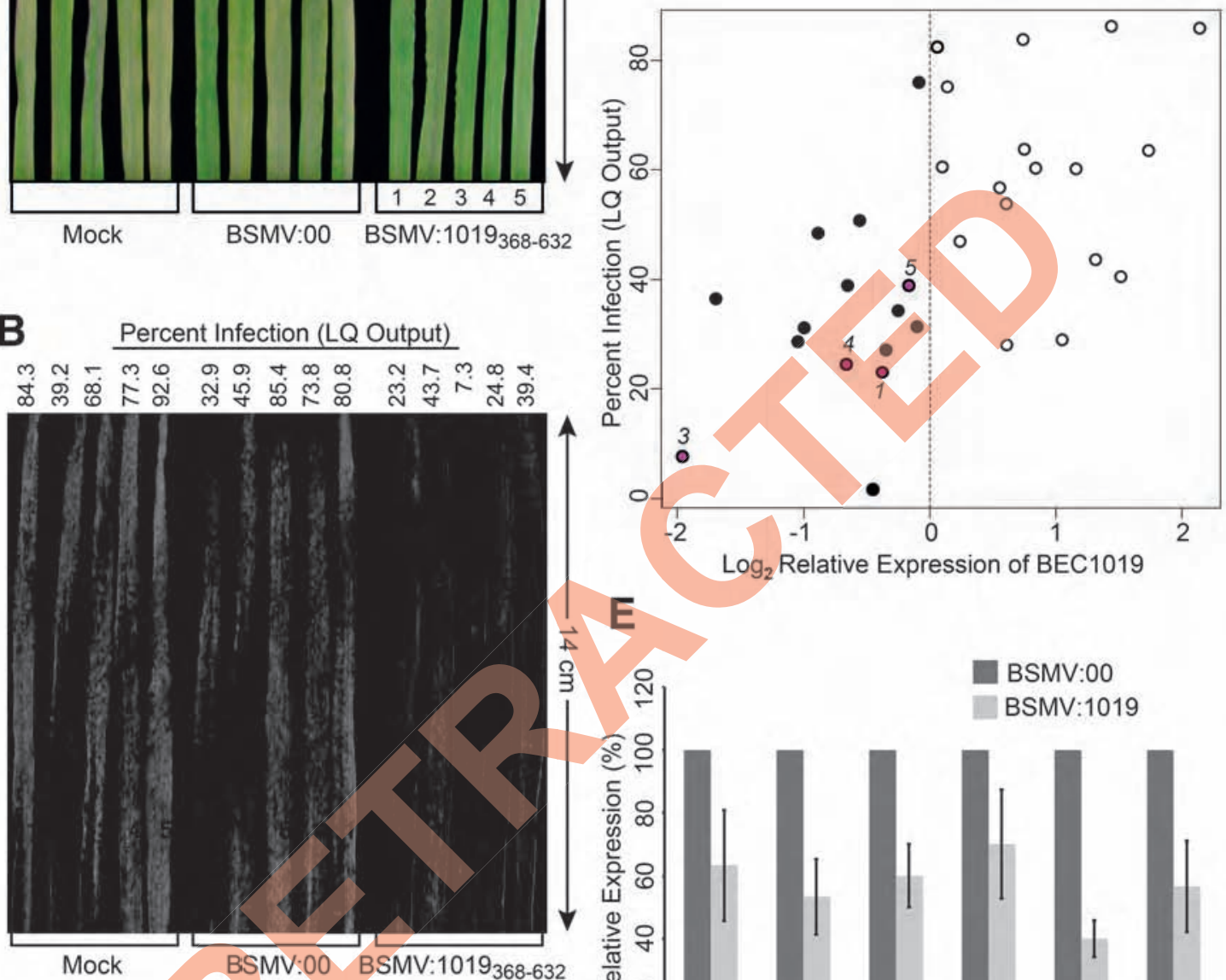

E

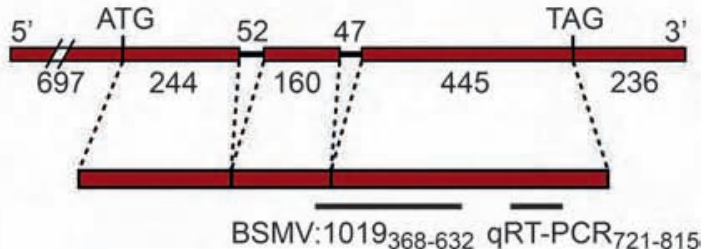

D

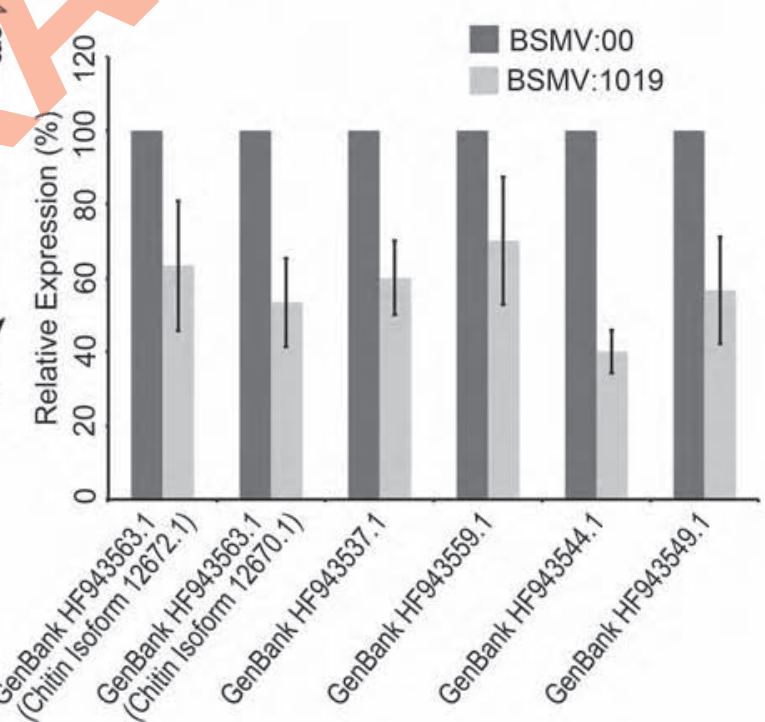

Fig. 1. Barley stripe mosaic virus-induced gene silencing (BSMV-VIGS) of BEC1019 reduces hyphal fungal growth and conidiation. A, Leaves from barley cultivar HOR 11358 (Mla9) treated with the BSMV:1019 $368-632$ construct, with BSMV:00 (empty vector), or subjected to mock viral inoculation (Carborundum buffer), photographed 7 days following inoculation with compatible Blumeria graminis isolate 5874 (avr $r_{a 9}$ ). Each construct was used in four replicate experiments, with eight to ten plants per treatment, and each replicate yielded similar results. B, To quantify fungal growth, the image shown in A was grayscaled, using LeafQuant-VIGS. B. graminis is white, thus the extent of discoloration is used to quantify fungal biomass on the otherwise green leaf. LeafQuant (LQ) output is presented as percent infection above each leaf. C, B. graminis BEC1019 gene (top) and cDNA (middle), showing positions of primers for BSMV-VIGS and quantitative reverse transcription-polymerase chain reaction. D, B. graminis hyphal growth as a function of BEC1019 expression. Data points represent $\log _{2}$ relative expression in the third leaf of each of the 32 plants that were treated with the BSMV:1019 ${ }_{368-632}$ construct over the four replications. Target gene expression was calculated using the $2^{-\Delta C T}$ method in individual BSMV:1019 $368-632^{-t r e a t e d ~ a n d ~ B S M V: 00-t r e a t e d ~ p l a n t s ~(S c h m i t t g e n ~}$ and Livak 2008). B. graminis $\beta$-tubulin was used as a steady state control. Magenta-filled circles correspond to a subsample from leaves 1,3 , 4, and 5 in panel A (leaf 2 was not assayed due to poor RNA quality). BSMV:1019 368 -632-treated leaves with relative BEC1019 expression $<1$ (filled circles to the left of the middle line $)$ have significantly lower average percent infection $(P$ value $=0.0019)$ than BSMV:1019 ${ }_{368-632}$-treated leaves with relative BEC1019 expression $>1($ open circles to the right of the middle line). E, Relative expression of six B. graminis genes in BSMV:00 versus BSMV:1019 $368-632$-treated leaves. Fold change was calculated by dividing the expression mean value for the targeted gene in BEC1019-silenced plants by the mean value measured in BSMV:00-treated plants. 
with strain BLS256 as elicitor or with strain 756C delivering a distinct $\mathrm{HR}$ inducer allows titration of the relative amounts to screen for quantitative effects (Makino et al. 2006). To assess the degree of HR to infiltrated bacterial strains, we developed a second MATLAB image-processing program, LeafQuant-T3S (discussed below).

The coding sequence for BEC1019 without its predicted signal peptide was fused to the $3^{\prime}$ end of the sequence encoding the T3S signal of AvrBs2 from $X$. campestris pv. vesicatoria (Minsavage et al. 1990; Mudgett et al. 2000) by cloning into a new broad-host range expression vector, pYM5. When infiltrated into barley leaves, neither $X$. campestris pv. raphani 756C expressing the AvrBs2 T3S signal terminated by a stop codon (AvrBs2') nor the BEC1019 fusion (AvrBs2':BEC1019) elicited a visible response, identical to untransformed $X$. campestris $\mathrm{pv}$. raphani $756 \mathrm{C}$ (Fig. 2; Table 1 ). X. oryzae pv. oryzicola BLS256 transformed with the AvrBs2':BEC1019 construct retained the ability of the untransformed strain to elicit HR in barley (not shown). To account for the possibility that any suppressor function of BEC1019 is quantitative, we carried out titrated coinoculations as alluded to above, using $X$. campestris pv. raphani $756 \mathrm{C}$ to deliver the AvrBs2':BEC1019 fusion and untransformed $X$. oryzae pv. oryzicola BLS256 as the elicitor. At a strain $756 \mathrm{C}$ to strain BLS256 ratio of $16: 1$, the HR normally elicited by X. oryzae pv. oryzicola BLS256 at that titer was suppressed (Fig. 2; Table 1). This suppressive effect was attributable to BEC1019, as neither AvrBs2' alone nor another B. graminis effector (BEC1038) expressed in the same way in X. campestris pv. raphani 756C suppressed the BLS256-elicited HR (Fig. 2; Table 1; Supplementary Fig. S1). Finally, the effect depended on an intact $X$. campestris pv. raphani 756C T3S system, as it was lost when AvrBs2':BEC1019 was expressed from the T3Sdeficient strain $756 \mathrm{C}$ derivative HW9 (T3S ${ }^{-}$) (Fig. 2; Table 1).

To determine whether BEC1019 promotes bacterial population growth in these nonhost interactions, bacteria were quantified immediately and at 3 and 6 days after infiltration by dilution plating of ground leaf segments. As shown in Table 2, populations of $X$. campestris pv. raphani $756 \mathrm{C}$ expressing AvrBs2' infiltrated alone remained steady throughout the experiment, while populations of that strain with coinfiltrated $X$. oryzae pv. oryzicola BLS256 declined tenfold, as expected for nonhost interactions without or with HR, respectively (Alfano and Collmer 1996). X. campestris pv. raphani $756 \mathrm{C}$ expressing AvrBs2':BEC1019 infiltrated alone showed no significant change in population size over time. In the coinfiltration with $X$. oryzae pv. oryzicola BLS256 however, BEC1019 prevented the drop in bacterial population size that occurred coincident with the HR when BEC1019 was not present. Thus, overall, the bacterial population data revealed no general bacterial growth promoting effect of BEC1019 in barley; however, the observed persistence of otherwise HR-inducing, nonhost bacterial populations in the presence of BEC1019 corroborates the role of BEC1019 as a defense suppressor.

\section{BEC1019 suppresses HR elicited by AvrPphB, a cysteine protease effector from Pseudomonas syringae pv. phaseolicola.}

Having found that BEC1019 suppresses cultivar-nonspecific HR induced by $X$. oryzae pv. oryzicola BLS256 in barley, we sought to further probe its function by asking whether it would suppress a cultivar-specific HR elicited by a characterized effector. We, thus, screened a collection of 73 diverse barley lines for HR to $X$. campestris pv. raphani 756C expressing the Pseudomonas syringae cysteine protease effector AvrPphB (Shao et al. 2003; Zhang et al. 2010). We selected this effector because it is known to target a protein kinase (PBS1) in Arabidopsis that is conserved across many flowering plant species (Caldwell and
Michelmore 2009; Shao et al. 2003), including barley (GenBank accession number AK368943). In Arabidopsis, cleavage of PBS1 by AvrPphB activates the NLR protein RPS5, which results in the HR (Ade et al. 2007; Qi et al. 2012; Shao et al. 2003; Simonich

A

\begin{tabular}{lccc}
\multicolumn{4}{c}{ Xoc +} \\
\hline Xcr & Xcr & Xcr & Xcr T3S- \\
& (AvrBs2') & (AvrBs2': & (AvrBs2':
\end{tabular}

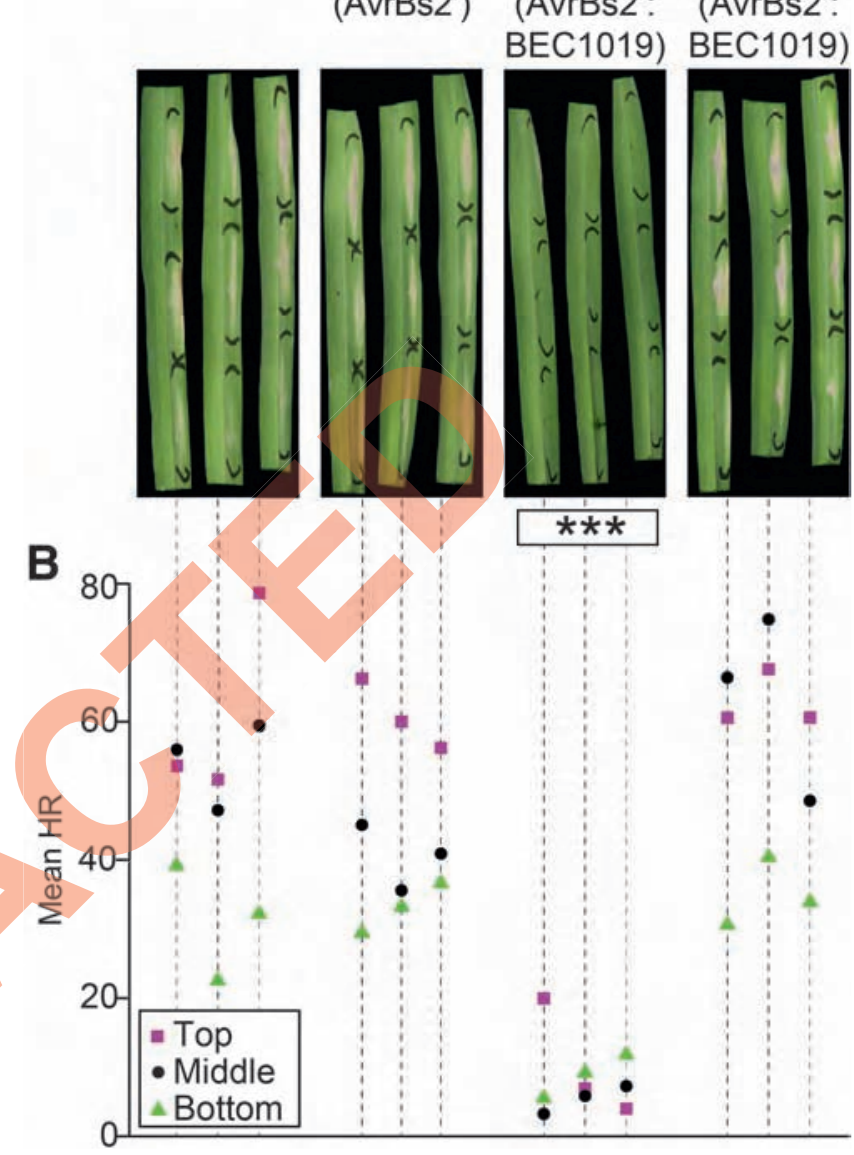

Fig. 2. BEC1019 delivered via the Xanthomonas type III secretion (T3S) system suppresses hypersensitive reaction (HR) elicited by $X$. oryzae pv. oryzicola BLS256 (Xoc) in barley. A, Primary leaves of barley line CI 16151 (Mla6) seedlings photographed 5 days after syringe infiltration with a mixed suspension of X. oryzae pv. oryzicola BLS256 cells and cells of X.campestris pv. raphani 736C or its T3S-deficient derivative HW9 (Xcr and $\mathrm{Xcr} \mathrm{T}_{3} \mathrm{~S}^{-}$, respectively) expressing the indicated protein constructs (in parentheses). AvrBs2', residues 1 to 97 of the Xanthomonas type III effector protein AvrBs2, comprising the T3S signal and stop codon; AvrBs2': BEC1019, residues 19 to 231 of BEC1019. AvrBs2' was expressed from pYMAJ1 and AvrBs2':BEC1019 from pYM5. X. oryzae pv. oryzicola BLS256 alone elicits HR and $X$. campestris pv. raphani $756 \mathrm{C}$ alone elicits no symptom (not shown). In each treatment, a cell suspension of the X.campestris pv. raphani $756 \mathrm{C}$ strain at an optical density at $600 \mathrm{~nm}$ $\left(\mathrm{OD}_{600}\right)$ of 0.8 was mixed $1: 1$ (by volume) with a cell suspension of $X$. oryzae pv. oryzicola $\mathrm{BLS} 256$ at $\mathrm{OD}_{600}$ of 0.05 for a $16: 1$ final cell ratio $\left(\mathrm{OD}_{600}\right.$ of 0.4 for $X$. campestris pv. raphani $756 \mathrm{C}$ and 0.025 for $X$. oryzae pv. oryzicola BLS256). Leaves were infiltrated when seedlings were 10 days old and the infiltrated area was delineated using a permanent marker. B, A dot plot showing the extent of HR (necrosis) resulting from each of the three infiltrations (top, middle, and bottom) in each leaf, aligned under the image of that leaf in A. The in-house image analysis software LeafQuant-T3Swas used to quantify necrosis (displayed as mean HR). The triple asterisk indicates $P<0.001$ for the difference between AvrBs2' and AvrBs2':BEC1019 delivered by wild-type $X$. campestris pv. raphani $756 \mathrm{C}$ as well as the difference between AvrBs2':BEC1019 delivered by the wild type versus the T3S- mutant. The experiment was repeated twice and each replicate showed the same result. The HR elicited by X. oryzae pv. oryzicola BLS256 in barley is cultivar nonspecific. 
and Innes 1995). Given that PBS1 is highly conserved, it seemed plausible that barley might also have an $\mathrm{R}$ protein analogous to RPS5 to monitor cleavage of the kinase. Indeed, our screen identified four lines (Diamond from Canada, Hv531 from Switzerland, PI452421 from the U. K., and WBDC 209 from Uzbekistan) that exhibited a HR specifically to $X$. campestris pv. raphani 756C expressing AvrPphB (Supplementary Fig. S2; Supplementary Table S1).

Hence, although AvrPphB is recognized by multiple dicot species, including common bean (Phaseolus vulgaris) (Jenner et al. 1991), pea (Pisum sativum) (Fillingham et al. 1992), and Arabidopsis (Simonich and Innes 1995), the results of this screen represent the first indication that it is recognized in monocots as well. Moreover, to our knowledge, AvrPphB is one of the few effectors known to trigger HR in both dicots and monocots.

Given the conservation of PBS1 in barley, the HR of the four lines to $\mathrm{AvrPphB}$ is consistent with the presence of a NLR protein that recognizes cleavage of the barley PBS1 by AvrPphB. More importantly for this study, these lines enabled us to assay the ability of BEC1019 to suppress the HR elicited by an effector known to be involved in ETI (Ade et al. 2007; Shao et al. 2003). We tested suppression by coinfiltrating $X$. campestris $\mathrm{pv}$. raphani 756C expressing AvrBs2':BEC1019 with 756C expressing AvrPphB, at a ratio of $8: 1$. In each of the four lines that showed HR in response to AvrPphB, AvrBs2' BEC1019 but not AvrBs2' alone suppressed that response (Fig. 3; Table 3).

\section{BEC1019 is broadly conserved.}

The functional assays presented above indicate that BEC1019 plays a key role in colonization of barley by B. graminis $\mathrm{f}$. sp. hordei, ostensibly by suppressing host defense. Thus, we sought to establish how widely distributed this protein is across diverse fungi. A BLASTp search of the BEC1019 amino acid sequence against the annotated proteins of 240 fungal genome sequences as of September 2013 from the National Center for Biotechnology Information (NCBI) nonredundant database (Johnson et al. 2008), the Fungal Genome Initiative (Broad Institute of Harvard and MIT), and the Department of Energy Joint Genome Institute
(Grigoriev et al. 2012) returned sequences from 96 species with an E value less than $1 \mathrm{e}^{-15}$, in addition to BEC1019 itself (Supplementary Table 2; Supplementary Fig. S3). These include homologs from every major fungal taxon in which at least five genomes have been sequenced. Individual species include plant pathogens and animal pathogens and one symbiont (a lichen) but also freeliving fungi. We submitted each of the homologs to OrthoMCL using Protocol 1 (Chen et al. 2006), and it placed 96 of the 97 in one ortholog group, OG5_142791. InterProScan also assigned the 96 in OG5_142791 to the same superfamily, SSF55486 (a metalloprotease "zincin" catalytic domain superfamily), and protein family, PFAM ID PF13933 (a putative peptidase family).

Subsequently, the default settings of MegAlign were used to generate a similarity tree of the 96 sequences in OG5_142791 (Fig. 4). Several major plant pathogens are found on the tree, including those that cause rice blast $(M$. oryzae), tan spot (Pyrenophora tritici-repentis), Stagonospora nodorum blotch of wheat, and northern and southern leaf blight of maize (Setosphaeria turcica and Cochliobolus heterostrophus, respectively). Several Fusarium species are also observed, including causal agents of Fusarium head blight of barley and wheat ( $F$. graminearum), and sudden death syndrome ( $F$. virguliforme) of soybean. Among the BEC1019 homologs from animal pathogens and free-living fungi are the characterized proteins Pra1 from Candida albicans (Citiulo et al. 2012), major allergen Asp F2 from Aspergillus fumigatus (Amich et al. 2010), and Zps1 (Lamb et al. 2001) from Saccharomyces cerevisiae. As of January 23, 2014, no hits were obtained from tBLASTn searches of BEC1019 in the sequences of the basidiomycete obligate biotrophs Puccinia graminis, $P$. striiformis, and $P$. recondita, however, a homolog was found in the basidiomycete corn smut pathogen, Ustilago maydis.

A multiple sequence alignment (MSA) was generated with MegAlign and was used to create a WebLogo (Crooks et al. 2004, Schneider and Stephens 1990). Six conserved cysteine residues are predicted by DISULFIND (Ceroni et al. 2006) to form three disulfide bonds spanning approximately 220 amino acids (Fig. 5). Two more cysteine residues were found at the

Table 1. Mixed linear model analysis of BEC1019 effect on Xanthomonas oryzae pv. oryzicola-elicited hypersensitive response ${ }^{\mathrm{a}}$

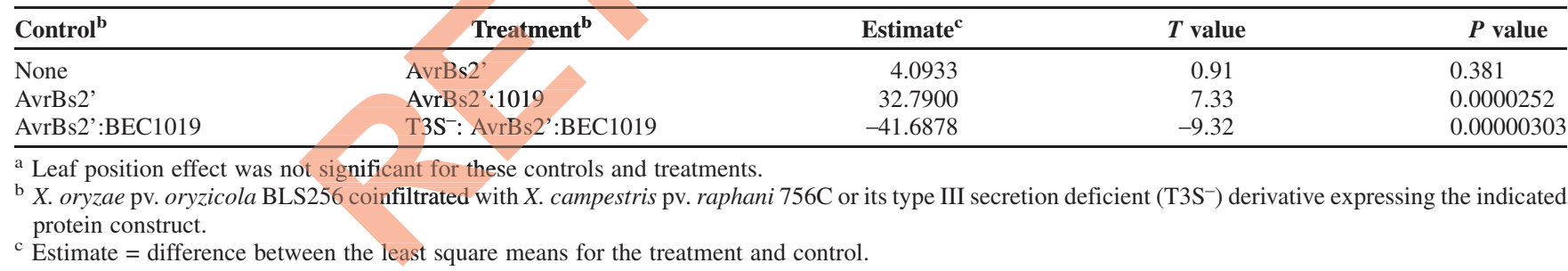

Table 2. Mixed linear model analysis of the effect of BEC1019 on populations of Xanthomonas spp. in infiltrated barley leaves ${ }^{\mathrm{a}}$

\begin{tabular}{|c|c|c|c|c|c|}
\hline \multirow[b]{2}{*}{ Treatment $^{\mathbf{b}}$} & \multicolumn{3}{|c|}{ Days after infiltration $^{c}$} & \multirow[b]{2}{*}{$F$ value } & \multirow[b]{2}{*}{$P$ value } \\
\hline & $\mathbf{0}$ & 3 & 6 & & \\
\hline X. campestris pv. raphani 756C (AvrBs2') & 4.17 & 3.50 & 3.83 & 4.00 & 0.0572 \\
\hline X. campestris pv. raphani $756 \mathrm{C}(\mathrm{AvrBs} 2$ ') + X. oryzae pv. oryzicola $\mathrm{BLS} 256$ & 4.83 & 4.50 & 0.45 & 23.42 & 0.000453 \\
\hline X. campestris pv. raphani 756C (AvrBs2':1019) & 4.00 & 3.83 & 3.50 & 0.50 & 0.622 \\
\hline $\begin{array}{l}\text { X. campestris pv. raphani } 756 \mathrm{C}(\text { AvrBs2':1019) }+ \text { X. oryzae pv. oryzicola } \\
\text { BLS256 }\end{array}$ & 5.50 & 5.67 & 5.50 & 0.07 & 0.932 \\
\hline X. campestris pv. raphani 756C (AvrBs2':1019: C152S) & 4.17 & 4.00 & 3.50 & 3.25 & 0.0927 \\
\hline $\begin{array}{l}\text { X. campestris pv. raphani } 756 \mathrm{C}(\text { AvrBs2':1019: C152S })+\text { X. oryzae pv. } \\
\text { oryzicola BLS256 }\end{array}$ & 5.50 & 4.67 & 0.32 & 849.45 & 4.83E-10 \\
\hline
\end{tabular}


C terminus of the B. graminis sequence and are predicted to form a fourth disulfide bond (Supplementary Fig. S4). Seven highly conserved motifs were found using MEME Suite (E value $1.0 \mathrm{e}^{-500}$ ) (Bailey et al. 2006), These include an ETVIC motif (E value, $2.6 \mathrm{e}^{-623}$ ) in 93 of 96 sequences as well as the HRxxH fungal allergen domain ( $E$ value, $1.1 \mathrm{e}^{-600}$ ) also present in all but three (Punta et al. 2012) (Fig. 5).

\section{The conserved ETVIC motif}

is required for suppression of $\mathrm{HR}$.

Eight conserved cysteine residues are predicted by DISULFIND (Ceroni et al. 2006) to form four disulfide bonds (Fig. 5). Four of the cysteines are present in three of the seven motifs. To assess whether these conserved cysteine residues, other residues in the ETVIC motif, or residues in the HRxxH motif are required for function, we performed site-directed mutagenesis and screened the resulting constructs (Supplementary Table 3) for loss of HRsuppressing activity in the T3S assay with $X$. oryzae pv. oryzicola BLS256 as elicitor (Fig. 6; Table 4). Substitution C152S in the ETVIC motif resulted in a decreased ability to suppress HR. Consistent with this result, bacterial populations dropped to the same extent seen in leaves infiltrated with $X$. oryzae pv. oryzicola BLS256 and the $X$. campestris pv. raphani $756 \mathrm{C}$ control expressing AvrBs2' (Table 2). Significantly, substitution at none of the other cysteine residues affected function, suggesting that none participates in a disulfide bond or that such bonds are not essential to BEC1019 HR suppression activity and, therefore, that the $\mathrm{C} 152 \mathrm{~S}$ effect is specific and not the result of general destabilization of the protein. Furthermore, two other substitutions in the ETVIC motif, V150A and I151A, like C152S, displayed a significant reduction in HR-suppressing activity (Table 4), supporting a specific functional role for $\mathrm{C} 152$ and the motif overall. Notably, none of the mutations in the highly conserved HRxxH motif altered HR suppression in this assay. Comparable stability of wild-type BEC1019 and the ETVIC and HRxxH mutant proteins were confirmed by Western blot analysis using epitope-tagged constructs (Supplementary Fig. S5).

Random forest analysis suggests lifestyle-associated residues.

In contrast to the motifs that are conserved across all BEC1019 homologs, we hypothesized that sequence variation specific to homologs in plant versus animal pathogens might exist. To investigate, we generated a random forest of classification trees (Breiman 2001a). Training data for construction of the random forest consisted of the fungal lifestyle (plant pathogen, animal pathogen, or free-living nonpathogen) and the residue at each position in the MSA for each of the 96 (OG5_142791) homologs. Each of 10,000 classification trees included in the forest was constructed from a bootstrap sample of the 96 sequences and produces a lifestyle prediction for any given fungus as a function of MSA residues.

To identify the MSA positions most associated with fungal lifestyle, we conducted a variable importance (VI) analysis as proposed by Breiman (2001b). For the analysis considered here, the importance of any particular MSA position is determined by how much the lifestyle misclassification error increases when the residues at the MSA position are shuffled within the position across the 96 sequences, prior to computing the random forest lifestyle prediction. If the misclassification error increases very little when residues at a position are shuffled, such a position is evidently not very important for lifestyle determination. Alternatively, if a misclassification error rises sharply following residue permutation, the residue distribution at such an MSA position is strongly associated with lifestyle. Furthermore, one can separately examine misclassification error changes for homologous sequences associated with a specific lifestyle to obtain lifestyle- specific VI measures. In summary, from the MSA of all homologs, random forest VI analysis can be used to identify MSA positions at which the distribution of residues is predictive of lifestyle.

Our analysis indicates that position 434 in the MSA consensus sequence has the highest VI value for correctly predicting the plant pathogen lifestyle. The top 10 positions are shown in Figure 7 and Supplementary Fig. S6. Position 434 corresponds to BEC1019 position Glu 208, 22 residues downstream of the HRxxH motif and on an exposed surface helix in a structural model for BEC1019 (Supplementary Fig. S7), generated using the Phyre 2 server (Kelley and Sternberg 2009). Three more of the top 10 MSA positions $(372,390$, and 391) for predicting plant pathogen lifestyle are between the ETVIC and

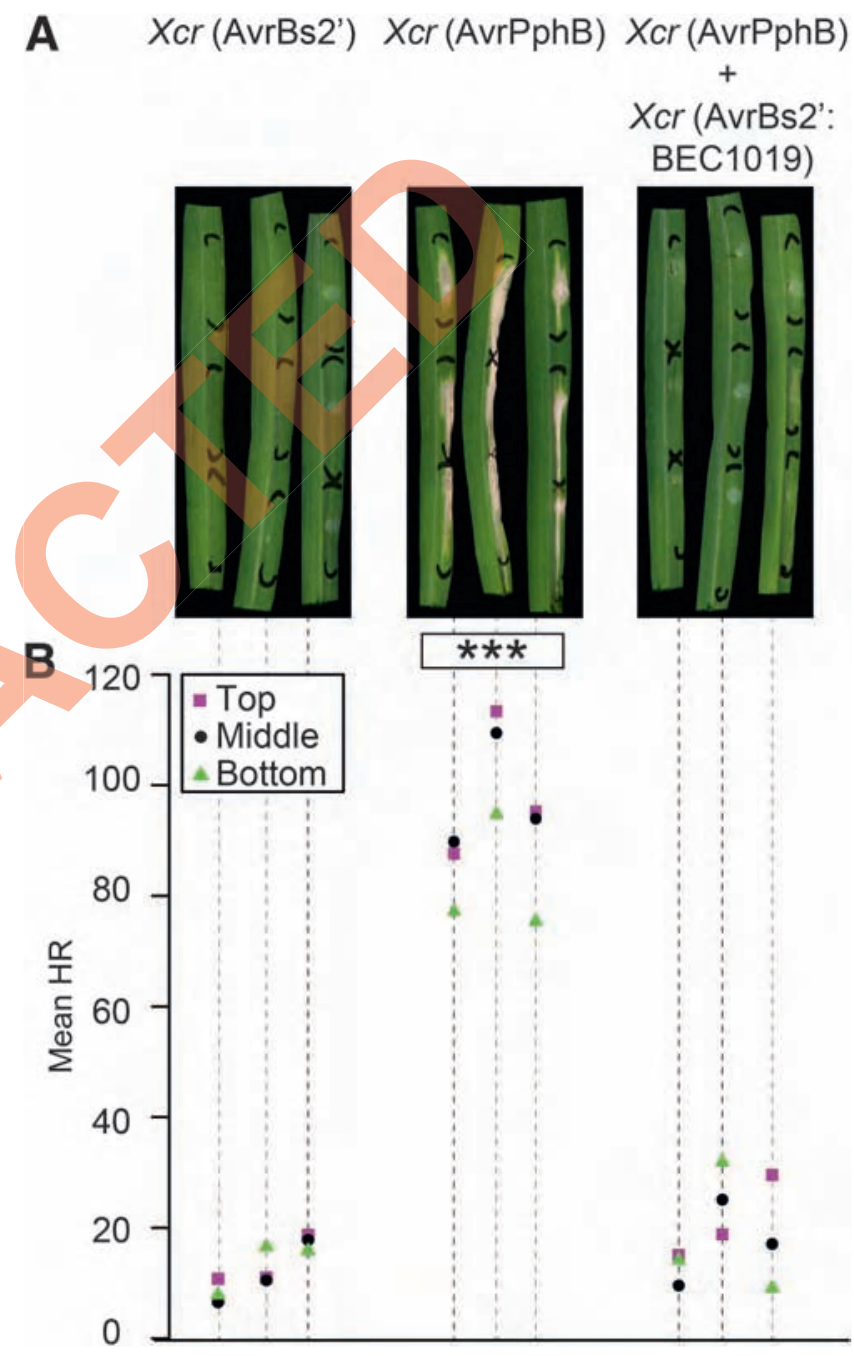

Fig. 3. BEC1019 delivered via the Xanthomonas type III secretion (T3S) system suppresses a cultivar-specific barley hypersensitive reaction (HR) triggered by the cysteine protease effector AvrPphB from Pseudomonas syringae pv. phaseolicola. A, Primary syringe-infiltrated leaves of barley cv. Diamond. X. campestris pv. raphani 756C (Xcr) (AvrBs2'), included as a reference for no $\mathrm{HR}$, was infiltrated at an optical density at $600 \mathrm{~nm}\left(\mathrm{OD}_{600}\right)$ of 0.4 , and $\mathrm{AvrPphB}$ was infiltrated at an $\mathrm{OD}_{600}$ of 0.05 . For the mixed suspension, AvrBs2':BEC1019 and AvrPphB were suspended at $\mathrm{OD}_{600}$ of 0.8 and 0.1 , respectively, and then, were mixed $1: 1$ (by volume) prior to infiltration. AvrPphB was expressed from a clone with its native promoter in plasmid pVSP61, which has the same backbone as pYM5 and pYMAJ1 but lacks the AvrBs2' fusion and the lac promoter. B, A dot plot showing the extent of HR (necrosis) resulting from each infiltration. The triple asterisk indicates $P<0.001$ for the difference between AvrBs2' and AvrPphB, as well as the difference between AvrPphB and (AvrPphB + AvrBs2':BEC1019). The experiment was repeated twice and each replicate showed the same result. 
HRxxH motifs, with the Phe at position 372 also occurring in an exposed helix and the other two (Ala at 390 and Thr at 391) in a surface loop. Another of the top 10, Ser 147, is at the junction of a $\beta$ sheet and a loop in the model and is a possible target for phosphorylation. Five of the remaining six positions $(222,285$, 344,345 , and 362) are on exposed loops. The final one, 553, in a relatively nonconserved region near the carboxyl end of the proteins, is not represented in the model.

\section{DISCUSSION}

Previously, we identified BEC1019 as one of a group of eight effector candidates that, in single-cell HIGS experiments, were shown to be important for $B$. graminis f. sp. hordei to form mature haustoria (Pliego et al. 2013). Here, using BSMV-VIGS, we were able to examine powdery mildew development in whole leaves, using a new image processing program and also to quantify expression of $B E C 1019$, using qRT-PCR to establish that, with BEC1019 silenced, B. graminis is less able to proliferate on the leaf surface (Fig. 1). In addition, using a vector we engineered for expression of proteins as fusions to the T3S signal of AvrBs2, we were able to further functionally characterize BEC1019 and determine that it suppresses both the barley cultivar-nonspecific HR induced by $X$. oryzae pv. oryzicola BLS256 (Fig. 2) and ETI induced by AvrPphB (Fig. 3). Taken together, these data support the conclusion that BEC1019 contributes to B. graminis virulence as a suppressor of host defense.

In the T3S assay, BEC1019 did not render barley susceptible to colonization by the nonhost pathogens $X$. campestris pv. raphani $756 \mathrm{C}$ or $X$. oryzae pv. oryzicola BLS256. Rather, it simply prevented the drop in bacterial populations that otherwise occurs as a result of the plant HR. This suggests that BEC1019 may interfere specifically and perhaps exclusively with the HR and not affect basal defenses. In a future study, it would be of interest to pursue this question by first testing whether BEC1019 can enhance barley susceptibility to diverse compatible pathogens that do not contain a native BEC1019, such as $X$. translucens, the causal agent of bacterial leaf streak, or Puccinia graminis tritici, the causal agent of stem rust.

With the exception of Polyporales, a classification under Basidiomycota, genes encoding homologs of BEC1019 are present in at least one species from every major fungal taxon in which a minimum of five genomes have been sequenced; in total, a homologous gene is present in 96 of 240 sequenced fungi. These fungi have diverse lifestyles, including obligate plant pathogens, necrotrophic animal pathogens, and freeliving nonpathogenic fungi. Most fungal effectors characterized to date share almost no sequence similarity to one another or to any known proteins (Stergiopoulos and de Wit 2009). Very few Blumeria effector candidates show clear homology to known proteins. This trend may simply reflect the fact that lack of homology to proteins outside the powdery mildews was considered an indicator of likely effector function in annotating the $B$. graminis genome (Pedersen et al. 2012; Spanu et al. 2010). Nonetheless, to our knowledge, only two fungal effectors are known to be conserved in multiple species. Ecp6, first identified in Cladosporium fulvum, is one of at least 17 homologs found in 12 species (Bolton et al. 2008). Ecp2, another $C$. fulvum effector, is a member of the Hce 2 superfamily, which comprises 153 homologs (many of them are paralogs within species) across 52 species (Stergiopoulos et al. 2012). The broad conservation of BEC1019 thus sets this effector apart and suggests that BEC1019 homologs, collectively and perhaps individually, play not only roles in pathogen-host interactions but also a yet-undefined, broader role in fungal ecology.

Conservation of multiple amino acid residues across the BEC1019 family, in particular the ETVIC motif, five additional cysteine residues, and the HRxxH motif (Fig. 5) suggested that these residues are important in the function of BEC1019. Sitedirected mutagenesis of each of these, however, identified only V150, I151, and C152 from the ETVIC motif as required for HR suppression in the T3S system assay (Fig. 6). Intriguingly, random forest analysis identified residues at several variable positions as highly correlated with plant parasitism (Fig. 7). Whether any is determinative awaits further experimentation, but all are predicted to be surface localized in a BEC1019 structural model, and thus, are available for interaction with a host molecule; also, several are in the vicinity of the functionally important ETVIC motif.

Several NLR R proteins contain an EDVID motif in the coiled coil (CC) domain. Mutation of the acidic residues $(\mathrm{E}$ and D) compromises binding of the CC domain to the barley MLA10 NLR (Rairdan et al. 2008) and abolishes activation of HR by full-length proteins (Bai et al. 2012). It may be that,

Table 3. Mixed linear model analysis of BEC1019 effect on AvrPphB-elicited hypersensitive response in different in diverse barley lines ${ }^{\text {a }}$

\begin{tabular}{|c|c|c|c|c|}
\hline Control $^{b}$ & Treatment $^{\mathbf{c}}$ & Estimate $^{\mathbf{d}}$ & $T$ value & $P$ value \\
\hline \multicolumn{5}{|l|}{ Diamond } \\
\hline AvrBs2' & AyrPphB & -79.3900 & -11.51 & $1.27 \mathrm{E}-13$ \\
\hline AvrPphB & AvrPphB + AvrBs2':1019 & 73.3289 & 10.63 & $1.17 \mathrm{E}-12$ \\
\hline \multicolumn{5}{|l|}{ Hv531 } \\
\hline AvrBs2' & AvrPphB & -28.4544 & -4.13 & 0.000208 \\
\hline AvrPphB & AvrPphB + AvrBs2’:1019 & 25.7256 & 3.73 & 0.000657 \\
\hline \multicolumn{5}{|l|}{ PI452421 } \\
\hline AvrBs2' & AvrPphB & -34.0778 & -4.94 & 0.0000180 \\
\hline AvrPphB & AvrPphB + AvrBs2':1019 & 31.7222 & 4.60 & 0.0000507 \\
\hline \multicolumn{5}{|c|}{ WBDC209 } \\
\hline AvrBs2' & AvrPphB & -55.6656 & -8.07 & $1.36 \mathrm{E}-09$ \\
\hline AvrPphB & AvrPphB + AvrBs2':1019 & 44.3989 & 6.44 & 0.000000181 \\
\hline \multicolumn{5}{|c|}{ CI 16151 (Mlab) } \\
\hline AvrBs2' & AvrPphB & -3.4800 & -0.50 & 0.617 \\
\hline AvrPphB & AvrPphB + AvrBs2’:1019 & 3.2378 & 0.47 & 0.642 \\
\hline \multicolumn{5}{|l|}{ Morex } \\
\hline AvrBs2' & AvrPphB & -3.4344 & -0.50 & 0.621 \\
\hline AvrPphB & AvrPphB + AvrBs2':1019 & -0.7567 & -0.11 & 0.913 \\
\hline
\end{tabular}

${ }^{a}$ Leaf position effect was not significant for these controls and treatments.

${ }^{\mathrm{b}} X$. campestris pv. raphani 756C expressing the indicated protein constructs singly or in combination by coinfiltration.

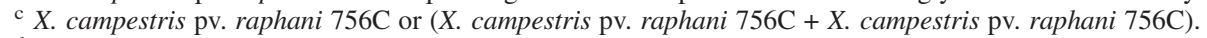

${ }^{\mathrm{d}}$ Estimate $=$ Difference between the least square means for the treatment and control. 
while the EDVID sequence in the R proteins is required to initiate $\mathrm{HR}$, the BEC1019 ETVIC motif is needed to suppress HR, possibly by competition for a common target. It is also important to note that an EIVIC motif in the putative metalloprotease effector
AVR-Pita from Magnaporthe oryzae (Jia et al. 2000; Orbach et al. 2000) is in a similar position to that of the BEC1019 ETVIC motif in the predicted structures of these proteins (Supplementary Fig. S8). The ETVIC motif does not coincide

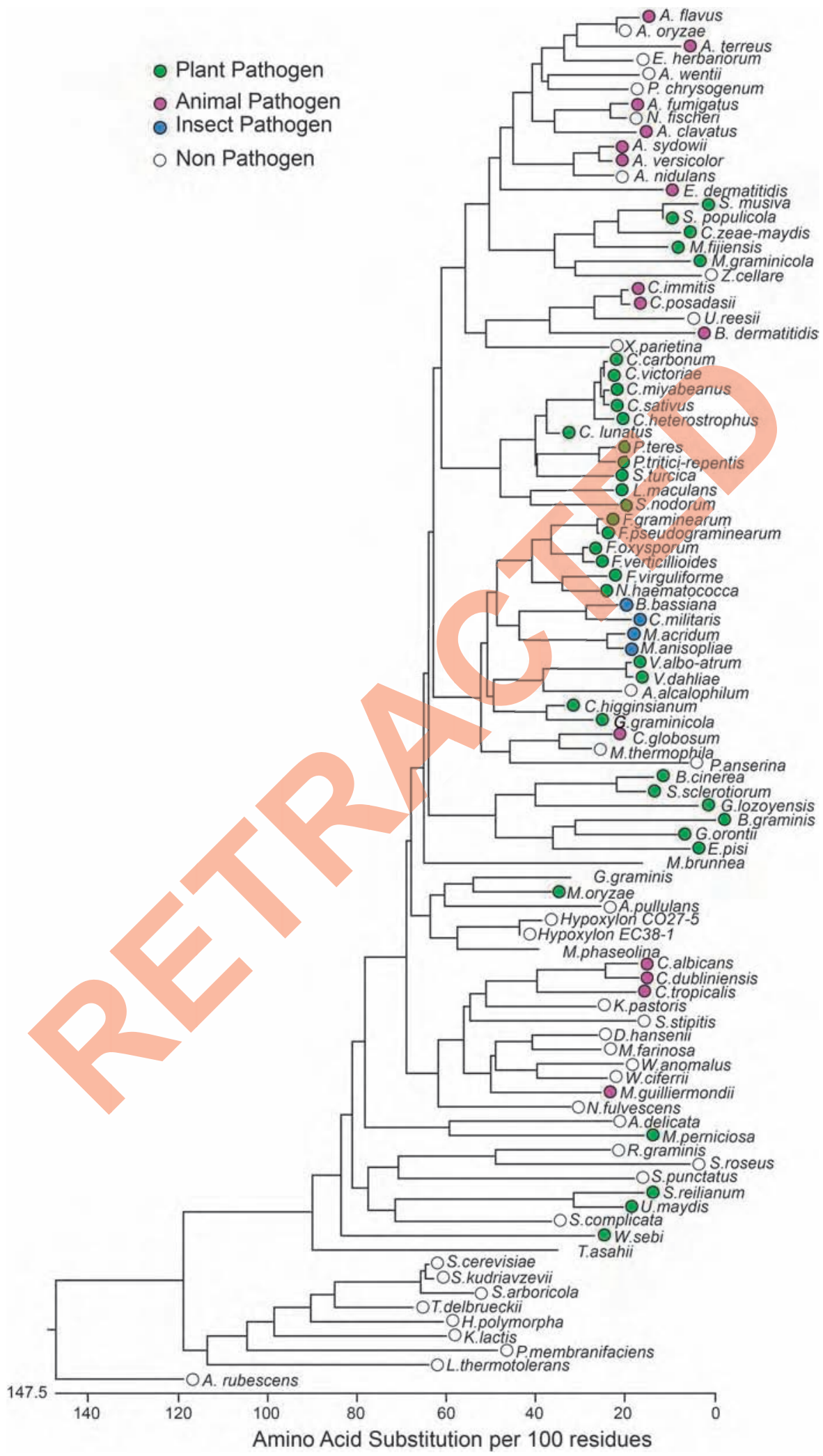

Fig. 4. Relatedness tree of BEC1019 and 95 homologs (ortholog group OG5_142791) identified via blastp queries of the National Center for Biotechnology Information nonredundant database, the Department of Energy Joint Genome Institute, and the Broad Institute Fungal Genome Initiative, followed by analysis in OrthoMCL (Chen et al. 2006). The tree is based on a multiple sequence alignment and was generated, along with the alignment, using MegAlign. With a few exceptions, this tree aligns with the taxonomic classifications of the represented species. 
in the structural models with catalytic site residues identified in deuterolysin, a structurally solved protease from Aspergillus oryzae that was used in the modeling (Fushimi et al. 1999; McAuley et al. 2001). Whether ETVIC is central to any proteolytic activity of BEC1019 (or AVR-Pita) or plays some other role remains to be tested.

That mutations in the HRxxH motif had no apparent effect on BEC1019 activity in the T3S assay leaves the importance of
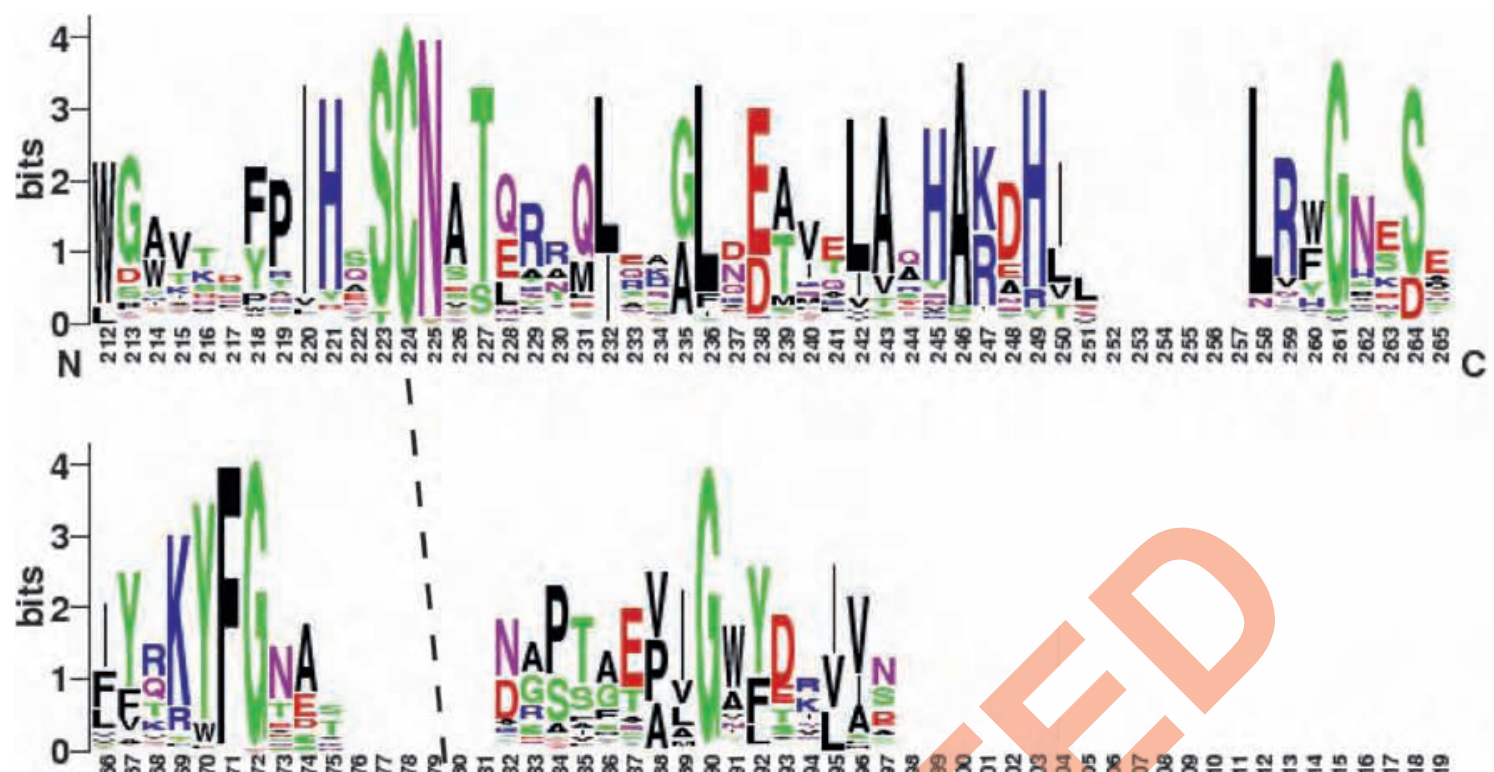

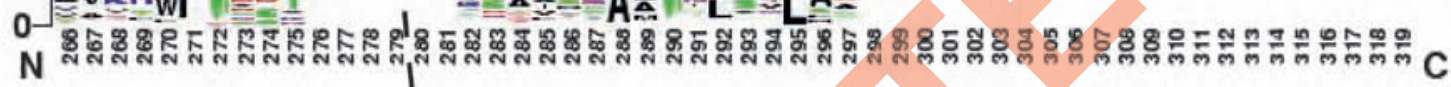
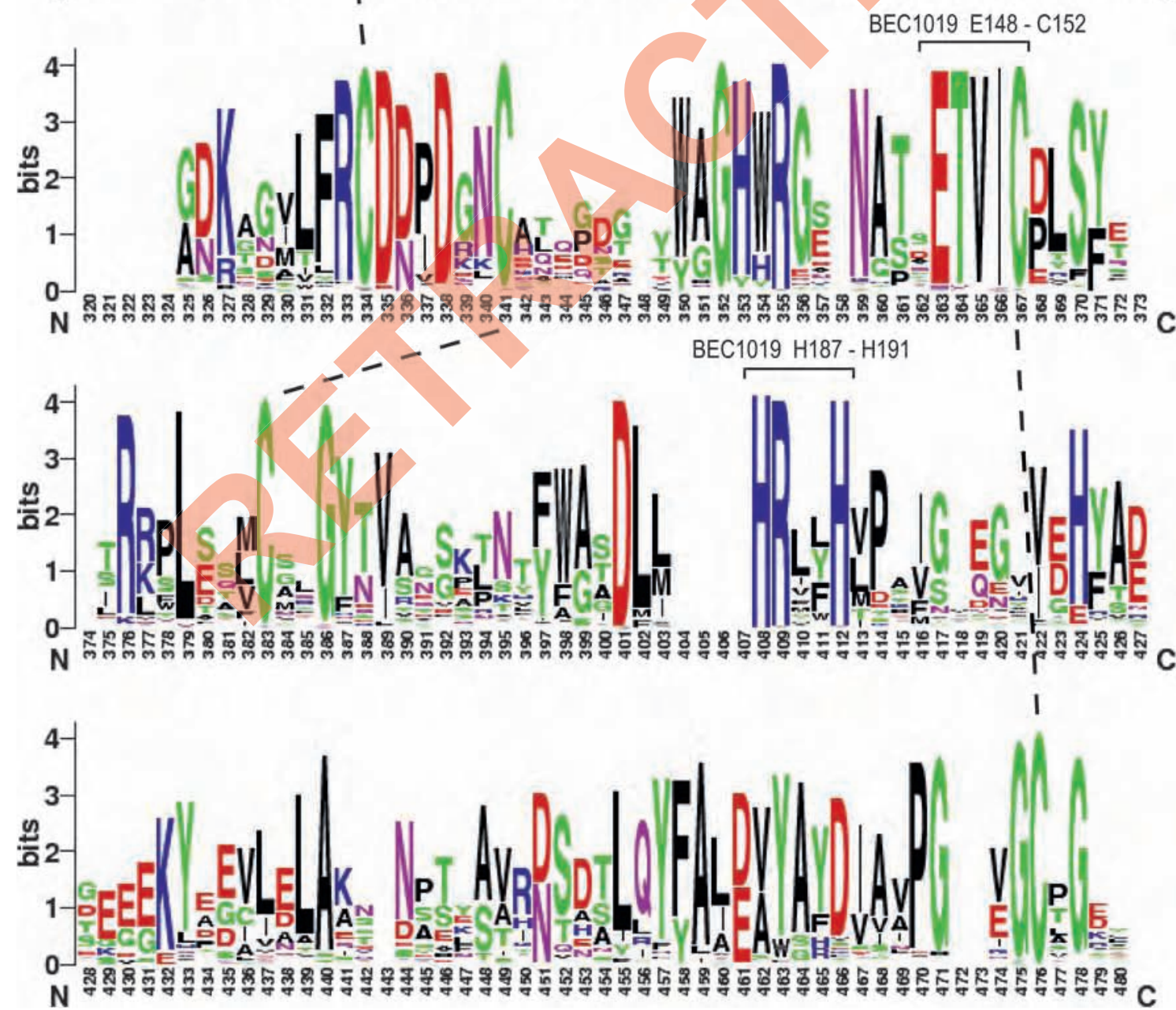

Fig. 5. Partial sequence logo for BEC1019 and homologs showing relative conservation of residues at different positions (corresponding to the height of the individual letters, codes for individual amino acids). The logo was generated using WebLogo and is based on the multiple sequence alignment generated using MegAlign. The ETVIC and HRxxH motifs are annotated with their positions in the BEC1019 sequence. Dotted lines indicate predicted disulfide bonds between cysteine residues, according to DISULFIND. 
this motif, if any, an open question. B. graminis secretes effector proteins from the haustorial membrane into the extrahaustorial matrix. The means by which some of those proteins then enter the host cell is currently unknown. Conceivably, HRxxH plays a role in translocation across the plant plasma membrane, following secretion by the fungus. Because the T3S system delivers proteins directly to the host cell cytoplasm, disruption of any translocation-related structure in BEC1019 would not be detected in that assay. Several studies have shown that oomycete effectors depend on an N-terminal RxLR motif for translocation (Sun et al. 2013; Tyler et al. 2013). HRxxH falls under a broad definition of the RxLR motif proposed by Kale and colleagues (2010), but it is located toward the C-terminus of BEC1019 and is part of a predicted cleft in the protein (Fig. 5).
Currently characterized as a "fungal allergen domain with unknown function" (Punta et al. 2012) (Pfam database), HRxxH is conserved in all but three of the identified BEC1019 homologs in OG5_142791, including those in free-living fungi. This observation suggests that instead of or in addition to any translocation function, HRxxH may serve a role unrelated to effector function. It is similar to the highly conserved metalloendoprotease signature HExxH (NCBI Conserved Domain Database entry cd11307). The two histidines in this motif represent two of three zinc-binding residues; the third residue is typically glutamic acid or aspartic acid (Vallee and Auld 1990). Though neither of the BEC1019 homologs Asp F2 and Pra1 has been shown to have protease activity when tested with casein as a substrate (Amich et al. 2010; Citiulo et al. 2012), Asp F2 plays a role in zinc acquisition (Amich et al. 2010) and Pra1 can

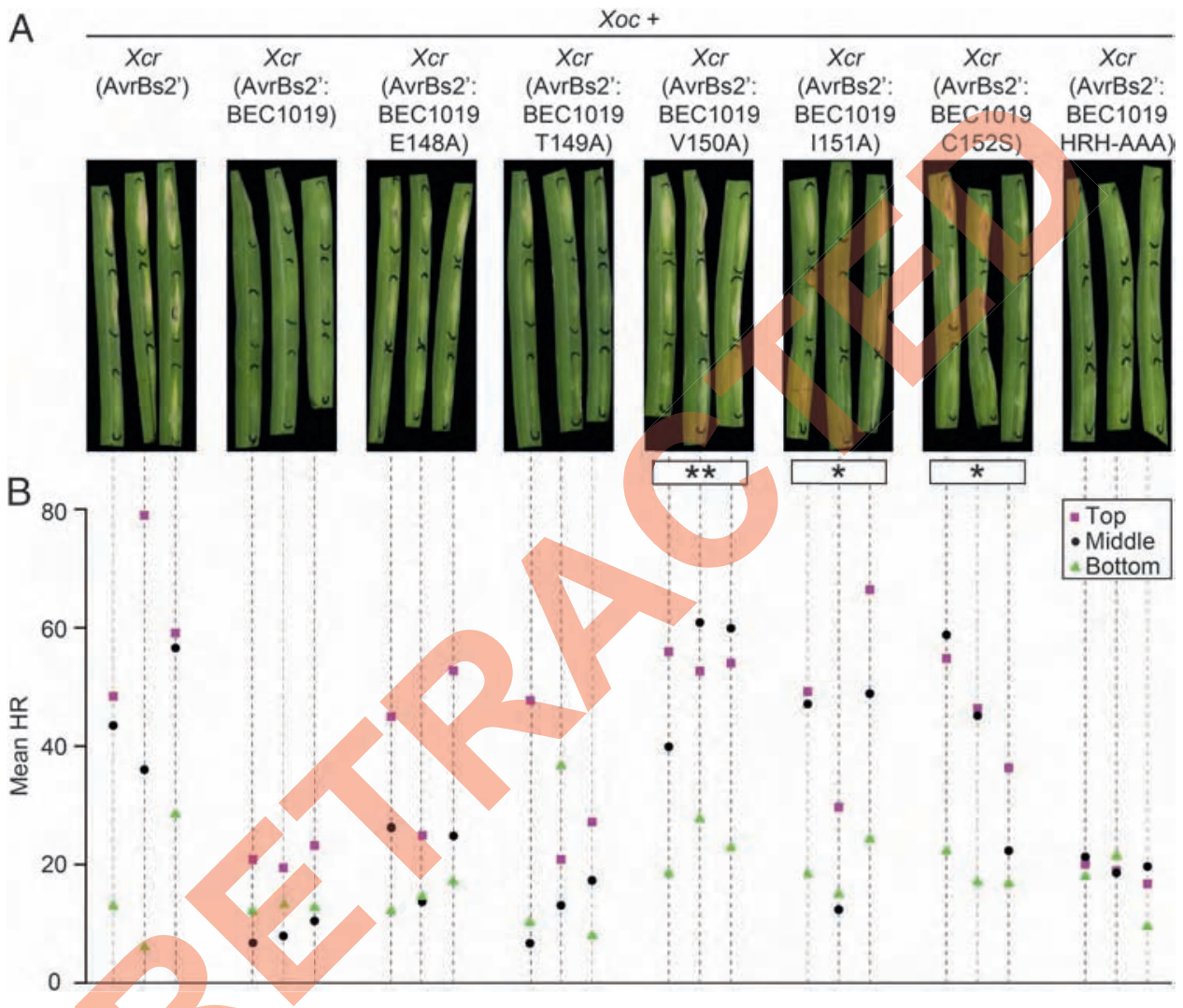

Fig. 6. Mutations within the ETVIC but not the HRxxH motif affect the HR suppressive function of BEC1019 delivered via the Xanthomonas type III secretion (T3S) system. A, Leaves of infiltrated barley line CI 16151, using the strains and constructs indicated, with site-specific amino acid substitutions. HRH-AAA is a triple substitution, H187A, R188A, and H191A. B, A dot plot showing the extent of HR (necrosis) resulting from each infiltration. A single asterisk over the dot plot for a mutant indicates adjusted $P<0.05$, and a double asterisk indicates adjusted $P<0.01$ for the difference between that mutant and the AvrBs2': BEC1019 wild-type. The experiment was repeated twice and each replicate showed the same result.

Table 4. Mixed linear model analysis of mean hypersensitive response (HR) for the role of the ETVIC motif in the effect of BEC1019 on Xanthomonas oryzae pv. oryzicola-elicited $\mathrm{HR}^{\mathrm{a}}$

\begin{tabular}{llcccc}
\hline Control $^{\mathbf{b}}$ & \multicolumn{1}{c}{ Treatment $^{\mathbf{b}}$} & Estimate $^{\mathbf{c}}$ & T-value $^{\prime}$ & \multicolumn{1}{c}{$\boldsymbol{P}$ value } & \multicolumn{1}{c}{ Adjusted $\boldsymbol{P}$ value $^{\mathbf{d}}$} \\
\hline AvrBs2' & AvrBs2':1019 & 27.0578 & -4.49 & 0.000370 & 0.00222 \\
AvrBs2':1019 & AvrBs2':1019: E148A & -11.6200 & 1.93 & 0.0717 & 0.215 \\
AvrBs2':1019 & AvrBs2':1019: T149A & -6.8033 & 1.13 & 0.275 & 0.497 \\
AvrBs2':1019 & AvrBs2':1019: V150A & -29.5256 & 4.90 & 0.000160 & 0.00112 \\
AvrBs2':1019 & AvrBs2':1019: I151A & -20.5211 & 3.41 & 0.00361 & 0.0145 \\
AvrBs2':1019 & AvrBs2':1019: C152S & -21.4899 & 3.57 & 0.00257 & 0.0129 \\
AvrBs2':1019 & AvrBs2':1019: HRH_AAA & -4.1900 & 0.70 & 0.497 & 0.497 \\
\hline
\end{tabular}

\footnotetext{
${ }^{a}$ Leaf position effect was not significant for these controls and treatments.

${ }^{\mathrm{b}}$ X. oryzae pv. oryzicola BLS256 coinfiltrated with X. campestris pv. raphani 756C expressing the indicated protein construct. $1019=\mathrm{BEC} 1019$.

${ }^{\mathrm{c}}$ Estimate $=$ Difference between the least square means for the treatment and control.

${ }^{\mathrm{d}} P$ values adjusted for multiple testing were obtained according to Hochberg (1988). Treatments with adjusted $P$ values $\leq 0.05$ were considered significantly different from the control.
} 
directly bind zinc (Citiulo et al. 2012). Three-dimensional modeling predicts that Pra1 interacts with the zinc transporter Zrt1, a protein also shown to be important for Candida albicans virulence (Citiulo et al. 2012). The Pral and Zrtl genes are physically linked in the Candida albicans genome and are transcriptionally coregulated, as they share a common promoter (Citiulo et al. 2012; Nobile et al. 2009). The B. graminis genome encodes two Zrt1 homologs. However, neither of those genes is physically linked to BEC1019 (Spanu et al. 2010). Similarly, the BEC1019 homolog in Magnaporthe oryzae is not linked to any Zrtl homolog, though in Ustilago maydis, the BEC1019 homolog is found next to a zinc transporter gene (Citiulo et al. 2012). Whether BEC1019 binds zinc or interacts with any zinc transporter, whether those properties involve the $\mathrm{HRxxH}$ motif, and how they may benefit the fungus remain to be tested.

The possible dual or even multiple roles of BEC1019 suggest a plausible path for effector evolution in which a protein that serves a conserved function of fundamental importance across many fungal lifestyles proves adaptive for symbiosis or is repurposed specifically for interaction with a host. It is conceivable, for example, that BEC1019 and its homologs detoxify certain antimicrobials, possibly peptides or reactive oxygen species (ROS) and that this function depends on the conserved motifs. Such a function would be advantageous for free-living or pathogenic fungi and might have been particularly adaptive for plant biotrophs. Indeed, localization to the host cell cytoplasm and scavenging of ROS there could be the mechanism of HR suppression; this would not be a neofunctionalization per se but a localization-dependent repurposing. It is important to note, however, that, although BEC1019 functioning inside the host cell to suppress HR is a compelling hypothesis supported by our data, we cannot exclude the possibility that BEC1019 contributes to $B$. graminis colonization by protecting the fungus from antimicrobials in the extrahaustorial matrix and that the HR suppression is a byproduct of type III delivery of BEC1019 activity into the host cell.

In any case, the broad distribution of the BEC1019 family of proteins, including several highly conserved motifs, underscores the notion that proteins clearly can retain core features that perform important roles in diverse contexts. The BEC1019 family, in which different members function in pathogenesis of plants versus animals, may provide an opportunity to discover broadly effective means of controlling fungal growth and infections important in both medicine and agriculture (Rovenich et al. 2014).

\section{MATERIALS AND METHODS}

Plant material and fungal isolates for VIGS assay.

Seedlings of barley lines CI 16151 (Mla6) (Moseman 1972), HOR11358 (Mla9), and CIho 2277 (Black Hull-less) were grown in a temperature-controlled greenhouse with supplemental lighting. Following BSMV-VIGS, plants were transferred to a temperature-controlled growth chamber with a 16-h photoperiod, with light intensity ranging from 400 to $1,000 \mu \mathrm{mol} \mathrm{m}^{-2} \mathrm{~s}^{-1}$, and day and night temperatures of 24 and $20^{\circ} \mathrm{C}$, respectively. B. graminis f. sp. hordei isolate $5874\left(a v r_{a 9}\right)$ was propagated on Hordeum vulgare cv. Morex in a controlled growth chamber at $18^{\circ} \mathrm{C}$ (16 h of light and $8 \mathrm{~h}$ of darkness).

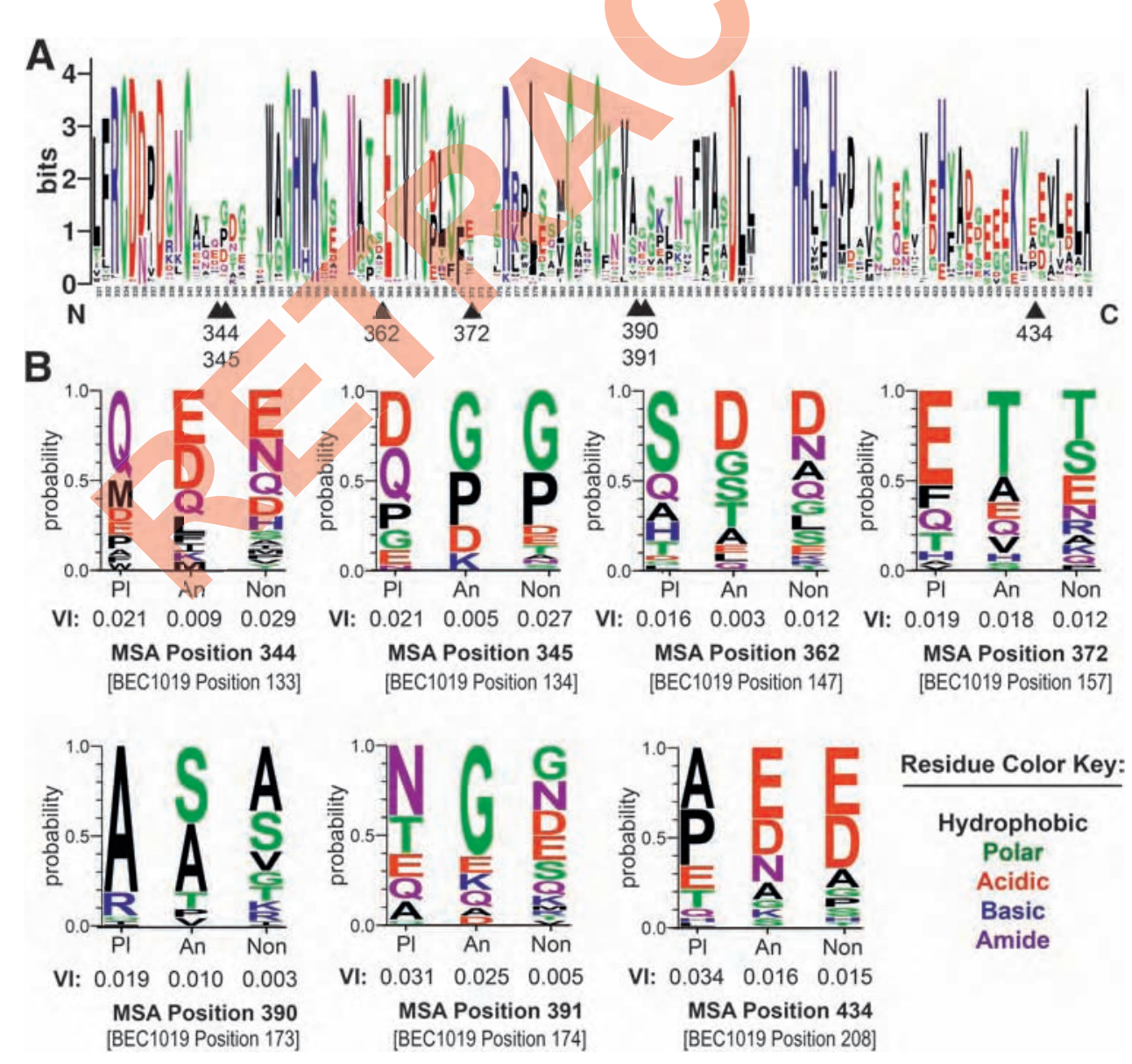

Fig. 7. Random forest analysis of the alignment of BEC1019 and homologs. Ten positions total correlated with at least two of three fungal lifestyles: plant pathogen (Pl), animal pathogen (An), or nonpathogen (Non). A, Location of seven central positions in the multiple sequence alignment (MSA). B, Sequence logos at each position generated with homologs grouped by lifestyle. Position within BEC1019 is also given. VI = variable importance measure. 


\section{BSMV-VIGS.}

A 264-bp region in the middle of the BEC1019 gene was amplified by PCR, using primers that add PacI and NotI restriction sites to the $5^{\prime}$ and $3^{\prime}$ ends, respectively. These sites enabled ligation of the fragment in antisense orientation into the BSMV: $\gamma$ vector (Meng et al. 2009). The resulting construct was designated BSMV:1019368-632 (Fig. 1C). BEC1019 was silenced in $B$. graminis isolate 5874 by mechanical infection of 7-day-old seedlings of the barley host cultivar HOR 11358 (Mla9) with homogenate from plants previously infected by BSMV:1019 ${ }_{368-632}$ via biolistic bombardment (Halterman and Wise 2004).

The control construct BSMV:00 was tested in the same way. Mock inoculation used homogenate of plants not infected with BMSV. Plants were maintained for 12 days in a growth chamber (Percival Scientific, Perry, IA, U.S.A.) with $16 \mathrm{~h}$ of light at $24^{\circ} \mathrm{C}\left(550 \mu \mathrm{mol} \mathrm{m} \mathrm{m}^{-2} \mathrm{~s}^{-1}\right)$ and $8 \mathrm{~h}$ of dark at $20^{\circ} \mathrm{C}$. Plants were then inoculated with B. graminis isolate 5874 $\left(a v r_{a 9}\right)$ conidiospores (compatible interaction with HOR 11358 ) and were maintained in a growth chamber with $16 \mathrm{~h}$ of light and $8 \mathrm{~h}$ of dark at $18^{\circ} \mathrm{C}$. The infection phenotype was monitored for 7 days.

\section{Imaging of $\boldsymbol{B}$. graminis infection phenotypes.}

At 7 days after powdery mildew inoculation, for each treatment (Mock, BSMV:00, and BSMV:1019 ${ }_{368-632}$ ), five of the plants inoculated were randomly selected and the third leaf of each was harvested. The set of five leaves for each treatment was photographed at high resolution $(2,592$ pixels $\times 3,456$ pixels, i.e., 9 Megapixels at a 4:3 aspect ratio), using a Canon PowerShot SX110 IS and the Vidpro professional Photo and Video LED light kit model Z-96K. The leaves were set on black felt for uniform, high-contrast background. Immediately after imaging, the leaves were frozen in liquid nitrogen and stored at $-80^{\circ} \mathrm{C}$. This process was repeated for the remaining plants in the experimental replicate.

\section{LeafQuant-VIGS.}

Images of $B$. graminis infection phenotypes had two important qualities: (i) there was high color contrast between the background (i.e., the black felt) and the leaves, and (ii) images were high resolution (approximately 9 Megapixels at a 4:3 aspect ratio). An application named LeafQuant-VIGS was developed, using MathWorks MATLAB 7.14 and Image Processing Toolbox 8.0, to analyze these images to find discoloration on leaves as a measure of $B$. graminis infection-associated biomass. LeafQuant-VIGS software is offered under MIT license via the GitHub repository.

LeafQuant-VIGS analysis takes the following steps to convert an RGB image from the camera into a grayscale image where the discoloration of leaves is proportional to the grayscale.

i. User input of parameters. LeafQuant-VIGS MATLAB function is defined as LeafQuant_v1(exprID, repID, cropImageFirst, showHistogram, numOfLeaves, exposureVal). ExprID and repID are strings representing experiment and replicate identification for user reference. CropImageFirst is a Boolean flag where, if true, the interface will let the user choose an area of the image to analyze, and, if false, the application will process the entire image. ShowHistogram is also a Boolean flag, which, if true, a histogram of infection level per leaf will be shown. NumOfLeaves is an integer specifying the number of leaves that are expected in the image or cropped region. ExposureVal is a multiplier for the nongreen pixel colors that are subtracted from the green channel. For example, a value of 2 would subtract the color contribution of the red and blue channels from the green channel twice.

ii. Detection of background and leaves as separate components in the image. This step exploits the high color contrast between the background and the leaves. Otsu's method (Otsu 1979) is a histogram-based threshold selection method. LeafQuant-VIGS uses its implementation provided in the Image Processing Toolbox to separate the background from the foreground (i.e., leaves). Leaf boundaries are detected using an 8-connected neighborhood method implemented in MATLAB Image Processing Toolbox.

iii. Conversion of background to uniform black. LeafQuantVIGS makes the background uniformly black before beginning to convert the image to grayscale for the purpose of quantification.

iv. Conversion of the leaves from RGB to grayscale colors. Every pixel of an RGB image shows a color based on the contribution from three primary color channels (red, green, blue). To find the amount of discoloration (hyphal growth) of a pixel on a green leaf, the contribution from the green channel has to be removed. The following formula is used to remove the contribution of the green channel from each of the red and blue color channels, and the resulting value is stored in a separate channel. This transforms the image into a grayscale image.

PixelValue $=$ GVal $-\{$ exposureVal $*[(\mathrm{GVal}-\mathrm{RVal})+$ $(\mathrm{GVal}-\mathrm{Bval})]\}$ for PixelValue $\geq 0$,

else PixelValue $=0$.

Once the image is converted to grayscale, a count of pixels in various gray intensity levels is saved. LeafQuant-VIGS provides histograms of the discoloration distribution per leaf, and it reports the mean, median, and quantiles of the results as a csv (comma separated values) file for further processing.

\section{Statistical analysis of LeafQuant-VIGS data.}

Four separate linear mixed model analyses of the LeafQuantVIGS data were conducted. All models used percent infection as the response and included random effects for replications and images within replications. The first model was used to test the significance of a single fixed slope coefficient on $\log _{2}$ relative expression of BEC1019 in BSMV:1019 $368-632$ treated leaves $(P$ value $=0.0071)$. The second model was used to compare the mean percent infection of BSMV:00 treated leaves with the mean percent infection for BSMV:1019 $368-632$ treated leaves that had relative BEC1019 expression less than 1.0 (the $P$ value for this analysis was 0.0046$)$. Thus, this model involved a single fixed factor with two levels (one level for each of the two leaf types: BSMV:00 versus BSMV:1019 $368-632$ with relative expression $<1.0$ ). The third model was used to compare the mean percent infection of BSMV:00-treated leaves with the mean percent infection for BSMV:1019368-632-treated leaves that had relative BEC1019 expression greater than 1.0 (this analysis had a $P$ value of 0.5109 ). This model also involved a single fixed factor with two levels (BSMV:00 versus BSMV: 1019368-632 with relative expression $>1.0$ ). The fourth model was applied to BSMV:1019 $368-632$-treated leaves to compare the mean percent infection with relative expression less than 1.0 with the mean percent infection with relative expression greater than 1.0 (the $P$ value for this analysis was 0.0019 ). This model had a single factor defined by relative expression of BEC1019 (less than 1.0 versus greater than 1.0). 


\section{LeafQuant-T3S.}

Quantification of results in the T3S assay was performed using a variation of LeafQuant-VIGS called LeafQuant-T3S, developed using lessons learned from LeafQuant-VIGS. Like LeafQuant-VIGS, LeafQuant-T3S was developed using MathWorks MATLAB 7.14 and Image Processing Toolbox 8.0 to analyze images and find levels of discoloration on leaves. The images had the following important parameters: (i) there were multiple regions within a leaf to be quantified, (ii) regions for quantification were less well-defined compared with VIGS, and (iii) images were high resolution, similar to VIGS images. LeafQuantT3S will be offered under MIT license at the GitHub repository website.

LeafQuant-T3S analysis takes the following steps.

$i$. Manual selection of the infiltrated areas in a leaf within the image. Once MATLAB loads the image of leaves, the user is prompted to make a selection, elliptical in shape, on an infiltrated region of a leaf.

ii. Conversion of the nonselected region of the image to uniform black. LeafQuant-T3S crops the image at the edges of the selected region. Within that cropped image, the background and nonselected leaf regions are masked by conversion to uniform black.

iii. Conversion of the selected regions of the leaf from $R G B$ to grayscale colors. The cropped image from step ii is processed similarly to the method described for LeafQuant-VIGS (part iv).

Once the image is converted to grayscale, a count of pixels in various gray intensity levels is reported. Whereas in the VIGS images the percentage of leaf showing discoloration is an important metric, quantification in the T3S experiment is based on the average level of discoloration in a selected (infiltrated) region of a leaf. This allows comparison of the extent of HR in different infiltrations within and across leaves. LeafQuant-T3S reports values for individual spots as well as an average discoloration measure in the output.

\section{Statistical analysis of LeafQuant-T3S output.}

A mixed linear model analysis (Wolfinger et al. 2001) for the T3S data was performed using the SAS PROC MIXED procedure. Contrast statements in SAS were made for various two-way comparisons between treatment samples within an experiment. Comparisons were done both overall between treatments and also when controlling for position. The treatment, position, and their interaction were the fixed factors and replication for any treatment was the random factor. The $P$ values for multiple testing were adjusted according to Hochberg (1988). Subsequently, the mean infection for each treatment in an experiment was plotted using "gplots" in R software for all three positions (top, middle, bottom).

\section{qRT-PCR.}

Individual leaves stored at $-80 \mathrm{C}$ were pulverized in liquid nitrogen and total RNA was extracted using Trizol-like reagent (Caldo et al. 2004). Genomic DNA was degraded by RNasefree DNase I (Ambion, Austin, TX, U.S.A.). SuperScript III reverse transcription (Life Technologies, Carlsbad, CA, U.S.A.) was used to synthesize first strand cDNA using $2 \mu \mathrm{g}$ of total RNA and oligo $(\mathrm{dT})_{20}$ primer.

This cDNA was used as a template for qRT-PCR to determine expression of BEC1019 relative to B. graminis $\beta$-tubulin. Barley1 contig_3802 and contig_16884 from the Affymetrix GeneChip Genome Array 900515 (Close et al. 2004) (GenBank ID dbj|AK356480.1|), determined to be optimal steady state controls via the Fluctuation Filter tool at the Plant Expression database (Dash et al. 2012), were also included as references.
Primers for BEC1019 were designed to amplify a 3 ' fragment of the region used for the silencing construct (Fig. 1). The qRT-PCR was performed using a Bio-Rad iCycler (Bio-Rad, Hercules, CA, U.S.A.). Conditions for 20- $\mu$ l reactions using PerfeCTa SYBR Green FastMix for iQ (Quanta Biosciences, Gaithersburg, $\mathrm{MD}$, U.S.A.) were $95^{\circ} \mathrm{C}$ for $3 \mathrm{~min}$, followed by 40 cycles of $95^{\circ} \mathrm{C}$ for $15 \mathrm{~s}$ and $60^{\circ} \mathrm{C}$ for $1 \mathrm{~min}$, a melt curve was then determined by starting at $55^{\circ} \mathrm{C}$ for $10 \mathrm{~s}$, and then, increasing by $0.5^{\circ} \mathrm{C}$ every $10 \mathrm{~s}$ for 80 cycles. Three technical replicates for each biological sample were included in each experiment. Target gene expression was calculated using the $2^{-\Delta \mathrm{CT}}$ method. The fold change due to silencing was calculated by dividing the individual expression value for each BSMV:1019 $368-632$-treated leaf by the mean value measured in BSMV:00 treated plants (Schmittgen and Livak 2008).

\section{BEC1019 sequence analysis.}

The BEC1019 gene in the first published B. graminis f. sp. hordei genome sequence (Spanu et al. 2010) resides at the end of a contig. Sequence alignment with closely related homologs showed that it was likely truncated in this contig. We therefore examined alternative assemblies and identified a few in which the locus extended beyond the end of the original contig. This sequence was used to design primers for the amplification of a full-length BEC1019 cDNA, thus demonstrating the validity of the alternative genome assemblies at this locus, which was deposited in GenBank (KJ571201). In parallel, BEC1019 was identified as a protein expressed specifically in haustoria, annotated in $e$ !EnsemblFungi as CCU74634.1, bgh03531_mRNA and in UniProtKB as N1J6C9 (partial protein) (Bindschedler et al. 2011) but also annotated as CELP0023 (Pedersen et al. 2012).

The full-length amino acid sequence of BEC1019 was used as the query for a blastp search of the nonredundant protein sequence databases at NCBI (Johnson et al. 2008), the Broad Institute Fungal Genome Initiative, and the Department of Energy Joint Genome Institute (Grigoriev et al. 2012). Hits with an $\mathrm{E}$ value below $1 \times 10^{-15}$ were submitted to OrthoMCL (Chen et al. 2006), which placed 96 of the 97 in one ortholog group, OG5_142791. The 96 sequences from OG5_142791 were aligned together and a relatedness tree was drawn using the MegAlign program of the Lasergene software package (DNASTAR, Madison, WI, U.S.A.) with default settings. The MSA also served as input to generate the WebLogo (Crooks et al. 2004; Schneider and Stephens 1990). DISULFIND (Ceroni et al. 2006) was used to predict disulfide bonds in BEC1019.

\section{Bacterial culture and plant growth conditions for the T3S assay.}

Escherichia coli strains were grown using Luria-Bertani broth or agar at $37^{\circ} \mathrm{C}$. Xanthomonas strains were grown using glucoseyeast extract liquid or agar ( $2 \%$ glucose, $1 \%$ yeast extract) at $28^{\circ} \mathrm{C}$. Antibiotics were used for selection as follows $(\mu \mathrm{g} / \mathrm{ml})$ : ampicillin at 100; chloramphenicol, 10; kanamycin, 25; and spectinomycin, 25. Barley plants were grown in growth chambers at $21^{\circ} \mathrm{C}$ on a 16 -h light and 8 -h dark cycle under cool white, high-output fluorescent lights, maintained to provide 85 to 112 $\mu \mathrm{mol} / \mathrm{m}^{2} / \mathrm{s}$ at soil level. Autoclaved Cornell Mix (10.6 cubic ft. of compressed peat moss, 12 cubic $\mathrm{ft}$ of vermiculite, $20 \mathrm{lb}$ of dolomitic limestone, and $6 \mathrm{lb}$ of 11-5-11 fertilizer yielding approximately 1.2 cubic yards of mix) was used for potting. Plants were watered daily, starting from the third day after sowing.

\section{Plasmid constructs for the T3S assay.}

To construct the Gateway destination vector pYM5, first the avrRpt 2 coding sequence in broad host range plasmid pDD62 (avrBs2 ${ }_{1-97}+a v r R p t 2_{80-255}$ ) (Mudgett et al. 2000) was excised 
using HindIII and XhoI and was replaced with Gateway cassette reading frame $\mathrm{B}$ (Life Technologies) that had been previously cloned into pTOPO-TA (Life Technologies), yielding pYM1. For technical reasons, the reading frame was then changed to Reading Frame A, using the QuikChange site-directed mutagenesis kit (Agilent Technologies, Santa Clara, CA, U.S.A.), to create pYM5. Coding sequences for BEC1019, without the predicted signal peptide, were amplified via PCR and were cloned into pCR8 using TOPO cloning (Life Technologies) and mutations were made to BEC1019 using QuikChange mutagenesis (Agilent Technologies, Santa Clara, CA, U.S.A.); clones were then transferred into pYM5 by Gateway LR reaction (Life Technologies). In pYM5, the avrBs 2 coding sequence is preceded by the native $a v r B s 2$ promoter and, upstream of that, the lac promoter, which is constitutive in Xanthomonas. Negative control plasmid pYMAJ1 (expressing only the AvrBs2 T3S signal) was created by replacing the Gateway cassette in pYM5 with a double-stranded oligonucleotide that places a stop codon at the end of the avrBs 2 coding sequence and adds a diagnostic EcoRI site. For delivery of AvrPphB, a clone in pVSP61 with the native $a v r P p h B$ promoter and no translational fusion, described previously (Simonich and Innes 1995), was used. The progenitor of pYM5, pDD62, is a derivative of pVSP61, so all plasmids used share the same backbone, including the origin of replication.

\section{Xanthomonas T3S assay.}

Xanthomonas cells were harvested from plates cultured for $48 \mathrm{~h}$ at $28^{\circ} \mathrm{C}$ and were suspended in $10 \mathrm{mM} \mathrm{MgCl}$. Suspensions were diluted and mixed as specified in the figure legends and were then infiltrated into primary leaves of 10-day-old barley seedlings, using a needleless syringe. For each suspension mixture, three leaves were infiltrated at three different spots per leaf, using approximately $40 \mu \mathrm{l}$ per spot. Leaves were photographed and scored 5 days following infiltration. Plants were maintained in a growth chamber throughout. Experiments were repeated at least twice.

\section{Quantification of bacterial populations.}

At 0,3 , and 6 days after infiltration, leaf sections $1 \mathrm{~cm}$ in length centered on an infiltration spot were ground in $300 \mu \mathrm{l}$ of $10 \mathrm{mM} \mathrm{MgCl}$, and bacterial cells were quantified by dilution plating. A mixed linear model analysis was performed using the SAS PROC MIXED procedure to determine significance of differences in bacterial counts.

\section{ACKNOWLEDGMENTS}

The authors thank J. Abbott for accessing the alternative assemblies of the $B$. graminis f. sp. hordei genome that enabled us to derive the full-length BEC1019 gene. We thank Y. Meng and A. Jayasena for construction of pYM5 and pYMAJ1. We also thank M. Bhattacharyya for early access to $F$. virguliforme sequence. B. Steffenson provided several of the barley diversity lines. This research was supported in part by National Science Foundation Plant Genome Program grants 09-22746 to R. P. Wise, A. J. Bogdanove, D. Nettleton, and J. A. Dickerson, 13-39348 to R. P. Wise, D. Nettleton, A. J. Bogdanove, and R. W. Innes, and the National Institute of General Medical Sciences of the NIH grant R01 GM046451 to R. W. Innes.

\section{LITERATURE CITED}

Ade, J., DeYoung, B. J., Golstein, C., and Innes, R. W. 2007. Indirect activation of a plant nucleotide binding site-leucine-rich repeat protein by a bacterial protease. Proc. Natl. Acad. Sci. U.S.A. 104 2531-2536.

Ahmed, A. A., Pedersen, C., Schultz-Larsen, T., Kwaaitaal, M., Jørgensen, H. J. L., and Thordal-Christensen, H. 2015. Barley powdery mildew candidate secreted effector protein $\mathrm{CSEP}_{0105}$ inhibits the chaperone activity of a small heat shock protein. Plant Physiol. 168:321-333.
Alfano, J. R., and Collmer, A. 1996. Bacterial pathogens in plants: Life up against the wall. Plant Cell 8:1683-1698.

Amich, J., Vicentefranqueira, R., Leal, F., and Calera, J. A. 2010. Aspergillus fumigatus survival in alkaline and extreme zinc-limiting environments relies on the induction of a zinc homeostasis system encoded by the $z r f C$ and $a s p f 2$ genes. Eukaryot. Cell 9:424-437.

Ayliffe, M., Periyannan, S. K., Feechan, A., Dry, I., Schumann, U., Wang, M.-B., Pryor, A., and Lagudah, E. 2013. A simple method for comparing fungal biomass in infected plant tissues. Mol. Plant-Microbe Interact. 26:658-667.

Bai, S., Liu, J., Chang, C., Zhang, L., Maekawa, T., Wang, Q., Xiao, W., Liu, Y., Chai, J., Takken, F. L. W., Schulze-Lefert, P., and Shen, Q. H. 2012. Structure-function analysis of barley NLR immune receptor MLA10 reveals its cell compartment specific activity in cell death and disease resistance. PLoS Pathog. 8:e1002752.

Bailey, T. L., Williams, N., Misleh, C., and Li, W. W. 2006. MEME: Discovering and analyzing DNA and protein sequence motifs. Nucleic Acids Res. 34:W369-W373.

Bent, A. F., and Mackey, D. 2007. Elicitors, effectors, and $R$ genes: The new paradigm and a lifetime supply of questions. Annu. Rev. Phytopathol. 45:399-436.

Bindschedler, L. V., McGuffin, L. J., Burgis, T. A., Spanu, P. D., and Cramer, R. 2011. Proteogenomics and in silico structural and functional annotation of the barley powdery mildew Blumeria graminis f. sp. hordei. Methods 54:432-441.

Boller, T., and Felix, G. 2009. A renaissance of elicitors: Perception of microbe-associated molecular patterns and danger signals by patternrecognition receptors. Annu. Rev. Plant Biol. 60:379-406.

Boller, T., and He, S. Y. 2009. Innate immunity in plants: An arms race between pattern recognition receptors in plants and effectors in microbial pathogens. Science 324:742-744

Bolton, M. D., van Esse, H. P., Vossen, J. H., de Jonge, R., Stergiopoulos, I., Stulemeijer, I. J. E., van den Berg, G. C., Borrás-Hidalgo, O., Dekker, H. L., de Koster, C. G., de Wit, P. J., Joosten, M. H. A. J., and Thomma, B. P. H. J. 2008. The novel Cladosporium fulvum lysin motif effector Ecp6 is a virulence factor with orthologues in other fungal species. Mol. Microbiol. 69:119-136.

Breiman, L. 2001a. Random forests. Mach. Learn. 45:5-32.

Breiman, L. 2001b. Statistical modeling: The two cultures (with comments and a rejoinder by the author). Stat. Sci. 16:199-231.

Caldo, R. A., Nettleton, D., and Wise, R. P. 2004. Interaction-dependent gene expression in Mla-specified response to barley powdery mildew. Plant Cell 16:2514-2528.

Caldwell, K. S., and Michelmore, R. W. 2009. Arabidopsis thaliana genes encoding defense signaling and recognition proteins exhibit contrasting evolutionary dynamics. Genetics 181:671-684.

Ceroni, A., Passerini, A., Vullo, A., and Frasconi, P. 2006. DISULFIND: A disulfide bonding state and cysteine connectivity prediction server. Nucleic Acids Res. 34:W177-W181.

Cesari, S., Bernoux, M., Moncuquet, P., Kroj, T., and Dodds, P. N. 2014. A novel conserved mechanism for plant NLR protein pairs: The "integrated decoy" hypothesis. Front. Plant Sci. 5:606.

Chen, F., Mackey, A. J., Stoeckert, C. J., Jr., and Roos, D. S. 2006. OrthoMCL-DB: Querying a comprehensive multi-species collection of ortholog groups. Nucleic Acids Res. 34:D363-D368.

Citiulo, F., Jacobsen, I. D., Miramón, P., Schild, L., Brunke, S., Zipfel, P., Brock, M., Hube, B., and Wilson, D. 2012. Candida albicans scavenges host zinc via Pra1 during endothelial invasion. PLoS Pathog. 8: e1002777.

Close, T. J., Wanamaker, S. I., Caldo, R. A., Turner, S. M., Ashlock, D. A., Dickerson, J. A., Wing, R. A., Muehlbauer, G. J., Kleinhofs, A., and Wise, R. P. 2004. A new resource for cereal genomics: $22 \mathrm{~K}$ barley GeneChip comes of age. Plant Physiol. 134:960-968.

Crooks, G. E., Hon, G., Chandonia, J.-M., and Brenner, S. E. 2004. WebLogo: A sequence logo generator. Genome Res. 14:1188-1190.

Dash, S., Van Hemert, J., Hong, L., Wise, R. P., and Dickerson, J. A. 2012. PLEXdb: Gene expression resources for plants and plant pathogens. Nucleic Acids Res. 40:D1194-D1201.

DeYoung, B. J., Qi, D., Kim, S. H., Burke, T. P., and Innes, R. W. 2012. Activation of a plant nucleotide binding-leucine rich repeat disease resistance protein by a modified self protein. Cell. Microbiol. 14: 1071-1084.

Dörmann, P., Kim, H., Ott, T., Schulze-Lefert, P., Trujillo, M., Wewer, V., and Hückelhoven, R. 2014. Cell-autonomous defense, re-organization and trafficking of membranes in plant-microbe interactions. New Phytol. 204:815-822.

Ellingboe, A. H. 1972. Genetics and physiology of primary infection by Erysiphe graminis. Phytopathology 62:401-406. 
Fillingham, A. J., Wood, J., Bevan, J. R., Crute, I. R., Mansfield, J. W., Taylor, J. D., and Vivian, A. 1992. Avirulence genes from Pseudomonas syringae pathovars phaseolicola and pisi confer specificity towards both host and non-host species. Physiol. Mol. Plant Pathol. 40:1-15.

Fushimi, N., Ee, C. E., Nakajima, T., and Ichishima, E. 1999. Aspzincin a family of metalloendopeptidases with a new zinc-binding motif. Identification of new zinc-binding sites (His(128), His(132), and Asp (164)) and three catalytically crucial residues (Glu(129), Asp(143), and Tyr(106)) of deuterolysin from Aspergillus oryzae by site-directed mutagenesis. J. Biol. Chem. 274:24195-24201.

Grigoriev, I. V., Nordberg, H., Shabalov, I., Aerts, A., Cantor, M., Goodstein, D., Kuo, A., Minovitsky, S., Nikitin, R., Ohm, R. A., Otillar, R., Poliakov, A., Ratnere, I., Riley, R., Smirnova, T., Rokhsar, D., and Dubchak, I. 2012. The genome portal of the Department of Energy Joint Genome Institute. Nucleic Acids Res. 40:D26-D32.

Hacquard, S., Kracher, B., Maekawa, T., Vernaldi, S., Schulze-Lefert, P., and Ver Loren van Themaat, E. 2013. Mosaic genome structure of the barley powdery mildew pathogen and conservation of transcriptional programs in divergent hosts. Proc. Natl. Acad. Sci. U.S.A. 110:E2219-E2228.

Halterman, D. A., and Wise, R. P. 2004. A single-amino acid substitution in the sixth leucine-rich repeat of barley MLA6 and MLA13 alleviates dependence on RAR1 for disease resistance signaling. Plant J. 38:215-226.

Hochberg, Y. 1988. A sharper Bonferroni procedure for multiple tests of significance. Biometrika 75:800-802.

Jacob, F., Vernaldi, S., and Maekawa, T. 2013. Evolution and conservation of plant NLR functions. Front. Immunol. 4:297.

Jenner, C., Hitchin, E., Mansfield, J., Walters, K., Betteridge, P., Teverson, D., and Taylor, J. 1991. Gene-for-gene interactions between Pseudomonas syringae pv. phaseolicola and Phaseolus. Mol. Plant-Microbe Interact. 4:553-562.

Jia, Y., McAdams, S. A., Bryan, G. T., Hershey, H. P., and Valent, B. 2000. Direct interaction of resistance gene and avirulence gene products confers rice blast resistance. EMBO (Eur. Mol. Biol. Organ.) J. 19:4004-4014.

Johnson, M., Zaretskaya, I., Raytselis, Y., Merezhuk, Y., McGinnis, S., and Madden, T. L. 2008. NCBI BLAST: A better web interface. Nucleic Acids Res. 36:W5-W9.

Kale, S. D., Gu, B., Capelluto, D. G. S., Dou, D., Feldman, E., Rumore, A., Arredondo, F. D., Hanlon, R., Fudal, I., Rouxel, T., Lawrence, C. B. Shan, W., and Tyler, B. M. 2010. External lipid PI3P mediates entry of eukaryotic pathogen effectors into plant and animal host cells. Cell 142: 284-295.

Kamoun, S., Kamdar, H. V., Tola, E., and Kado, C. I. 1992. Incompatible interactions between crucifers and Xanthomonas campestris involve a vascular hypersensitive response: Role of the hrpX locus. Mol. PlantMicrobe Interact. 5:22-33.

Kelley, L. A., and Sternberg, M. J. E. 2009. Protein structure prediction on the Web: A case study using the Phyre server Nat. Protoc. 4:363-371.

Kjemtrup, S., Nimchuk, Z., and Dangl, J. L. 2000. Effector proteins of phytopathogenic bacteria: Bifunctional signals in virulence and host recognition. Curr. Opin. Microbiol. 3:73-78.

Kusch, S., Ahmadinejad, N., Panstruga, R., and Kuhn, H. 2014. In silico analysis of the core signaling proteome from the barley powdery mildew pathogen (Blumeria graminis f.sp. hordei). BMC Genomics $15: 843$.

Lamb, T. M., Xu, W., Diamond, A., and Mitchell, A. P. 2001. Alkaline response genes of Saccharomyces cerevisiae and their relationship to the RIM101 pathway. J. Biol. Chem. 276:1850-1856.

Macho, A. P., and Zipfel, C. 2014. Plant PRRs and the activation of innate immune signaling. Mol. Cell 54:263-272.

Makino, S., Sugio, A., White, F., and Bogdanove, A. J. 2006. Inhibition of resistance gene-mediated defense in rice by Xanthomonas oryzae pv. oryzicola. Mol. Plant-Microbe Interact. 19:240-249.

McAuley, K. E., Jia-Xing, Y., Dodson, E. J., Lehmbeck, J., Østergaard, P. R., and Wilson, K. S. 2001. A quick solution: $a b$ initio structure determination of a $19 \mathrm{kDa}$ metalloproteinase using ACORN. Acta Crystallogr. D Biol. Crystallogr. 57:1571-1578.

Meng, Y., Moscou, M. J., and Wise, R. P. 2009. Blufensin1 negatively impacts basal defense in response to barley powdery mildew. Plant Physiol. 149:271-285.

Meng, Y., and Wise, R. P. 2012. HvWRKY10, HvWRKY19, and HvWRKY28 regulate Mla-triggered immunity and basal defense to barley powdery mildew. Mol. Plant-Microbe Interact. 25:1492-1505.

Minsavage, G. V., Dahlbeck, D., Whalen, M. C., Kearney, B., Bonas, U., Staskawicz, B. J., and Stall, R. E. 1990. Gene-for-gene relationships specifying disease resistance in Xanthomonas campestris pv. vesicatoria pepper interactions. Mol. Plant-Microbe Interact. 3:41-47.

Moseman, J. G. 1972. Isogenic barley lines for reaction to Erysiphe graminis f. sp. hordei. Crop Sci. 12:681-682.
Mudgett, M. B., Chesnokova, O., Dahlbeck, D., Clark, E. T., Rossier, O., Bonas, U., and Staskawicz, B. J. 2000. Molecular signals required for type III secretion and translocation of the Xanthomonas campestris AvrBs2 protein to pepper plants. Proc. Natl. Acad. Sci. U.S.A. 97: 13324-13329.

Nobile, C. J., Nett, J. E., Hernday, A. D., Homann, O. R., Deneault, J.-S., Nantel, A., Andes, D. R., Johnson, A. D., and Mitchell, A. P. 2009. Biofilm matrix regulation by Candida albicans Zap1. PLoS Biol. 7: e1000133.

Nowara, D., Gay, A., Lacomme, C., Shaw, J., Ridout, C., Douchkov, D. Hensel, G., Kumlehn, J., and Schweizer, P. 2010. HIGS: Host-induced gene silencing in the obligate biotrophic fungal pathogen Blumeria graminis. Plant Cell 22:3130-3141.

Orbach, M. J., Farrall, L., Sweigard, J. A., Chumley, F. G., and Valent, B. 2000. A telomeric avirulence gene determines efficacy for the rice blast resistance gene Pi-ta. Plant Cell 12:2019-2032.

Otsu, N. 1979. A threshold selection method from gray-level histograms. Systems, Man and Cybernetics. IEEE T. Syst. Man. Cyb. 9:62-66.

Pedersen, C., Ver Loren van Themaat, E., McGuffin, L. J., Abbott, J. C., Burgis, T. A., Barton, G., Bindschedler, L. V., Lu, X., Maekawa, T., Wessling, R., Cramer, R., Thordal-Christensen, H., Panstruga, R., and Spanu, P. D. 2012. Structure and evolution of barley powdery mildew effector candidates. BMC Genomics 13:694.

Pliego, C., Nowara, D., Bonciani, G., Gheorghe, D. M., Xu, R., Surana, P., Whigham, E., Nettleton, D., Bogdanove, A. J., Wise, R. P., Schweizer, P., Bindschedler, L. V., and Spanu, P. D. 2013. Host-induced gene silencing in barley powdery mildew reveals a class of ribonuclease-like effectors. Mol. Plant-Microbe Interact. 26:633-642.

Punta, M., Coggill, P. C., Eberhardt, R. Y., Mistry, J., Tate, J., Boursnell, C., Pang, N., Forslund, K., Ceric, G., Clements, J., Heger, A., Holm, L., Sonnhammer, E. L. L., Eddy, S. R., Bateman, A., and Finn, R. D. 2012. The Pfam protein families database. Nucleic Acids Res. 40:D290-D301.

Qi, D., DeYoung, B. J., and Innes, R. W. 2012. Structure-function analysis of the coiled-coil and leucine-rich repeat domains of the RPS5 disease resistance protein. Plant Physiol. 158:1819-1832.

Rairdan, G. J., Collier, S. M., Sacco, M. A., Baldwin, T. T., Boettrich, T., and Moffett, P. 2008. The coiled-coil and nucleotide binding domains of the Potato Rx disease resistance protein function in pathogen recognition and signaling. Plant Cell 20:739-751.

Rentel, M. C., Leonelli, L., Dahlbeck, D., Zhao, B., and Staskawicz, B. J. 2008. Recognition of the Hyaloperonospora parasitica effector ATR13 triggers resistance against oomycete, bacterial, and viral pathogens. Proc. Natl. Acad. Sci. U.S.A. 105:1091-1096.

Rovenich, H., Boshoven, J. C., and Thomma, B. P. H. J. 2014. Filamentous pathogen effector functions: Of pathogens, hosts and microbiomes. Curr. Opin. Plant Biol. 20:96-103.

Schmidt, S. M., Kuhn, H., Micali, C., Liller, C., Kwaaitaal, M., and Panstruga, R. 2014. Interaction of a Blumeria graminis f. sp. hordei effector candidate with a barley ARF-GAP suggests that host vesicle trafficking is a fungal pathogenicity target. Mol. Plant Pathol. 15:535-549.

Schmittgen, T. D., and Livak, K. J. 2008. Analyzing real-time PCR data by the comparative C(T) method. Nat. Protoc. 3:1101-1108.

Schneider, T. D., and Stephens, R. M. 1990. Sequence logos: A new way to display consensus sequences. Nucleic Acids Res. 18:6097-6100.

Shao, F., Golstein, C., Ade, J., Stoutemyer, M., Dixon, J. E., and Innes, R. W. 2003. Cleavage of Arabidopsis PBS1 by a bacterial type III effector. Science 301:1230-1233.

Sharma, S., Sharma, S., Hirabuchi, A., Yoshida, K., Fujisaki, K., Ito, A., Uemura, A., Terauchi, R., Kamoun, S., Sohn, K. H., Jones, J. D. G., and Saitoh, H. 2013. Deployment of the Burkholderia glumae type III secretion system as an efficient tool for translocating pathogen effectors to monocot cells. Plant J. 74:701-712.

Simonich, M. T., and Innes, R. W. 1995. A disease resistance gene in Arabidopsis with specificity for the avrPph3 gene of Pseudomonas syringae pv. phaseolicola. Mol. Plant-Microbe Interact. 8:637-640.

Sohn, K. H., Lei, R., Nemri, A., and Jones, J. D. 2007. The downy mildew effector proteins ATR1 and ATR13 promote disease susceptibility in Arabidopsis thaliana. Plant Cell 19:4077-4090.

Spanu, P. D., Abbott, J. C., Amselem, J., Burgis, T. A., Soanes, D. M., Stüber, K., Ver Loren van Themaat, E., Brown, J. K. M., Butcher, S. A., Gurr, S. J., Lebrun, M.-H., Ridout, C. J., Schulze-Lefert, P., Talbot, N. J., Ahmadinejad, N., Ametz, C., Barton, G. R., Benjdia, M., Bidzinski, P., Bindschedler, L. V., Both, M., Brewer, M. T., Cadle-Davidson, L., CadleDavidson, M. M., Collemare, J., Cramer, R., Frenkel, O., Godfrey, D., Harriman, J., Hoede, C., King, B. C., Klages, S., Kleemann, J., Knoll, D., Koti, P. S., Kreplak, J., López-Ruiz, F. J., Lu, X., Maekawa, T., Mahanil, S., Micali, C., Milgroom, M. G., Montana, G., Noir, S., O’Connell, R. J., Oberhaensli, S., Parlange, F., Pedersen, C., Quesneville, H., Reinhardt, R., 
Rott, M., Sacristán, S., Schmidt, S. M., Schön, M., Skamnioti, P., Sommer, H., Stephens, A., Takahara, H., Thordal-Christensen, H., Vigouroux, M., Wessling, R., Wicker, T., and Panstruga, R. 2010. Genome expansion and gene loss in powdery mildew fungi reveal tradeoffs in extreme parasitism. Science 330:1543-1546.

Stergiopoulos, I., and de Wit, P. J. G. M. 2009. Fungal effector proteins. Annu. Rev. Phytopathol. 47:233-263.

Stergiopoulos, I., Kourmpetis, Y. A. I., Slot, J. C., Bakker, F. T., De Wit, P. J. G. M., and Rokas, A. 2012. In silico characterization and molecular evolutionary analysis of a novel superfamily of fungal effector proteins. Mol. Biol. Evol. 29:3371-3384.

Sun, F., Kale, S. D., Azurmendi, H. F., Li, D., Tyler, B. M., and Capelluto, D. G. S. 2013. Structural basis for interactions of the Phytophthora sojae RxLR effector Avh5 with phosphatidylinositol 3-phosphate and for host cell entry. Mol. Plant-Microbe Interact. 26:330-344.

Tyler, B. M., Kale, S. D., Wang, Q., Tao, K., Clark, H. R., Drews, K., Antignani, V., Rumore, A., Hayes, T., Plett, J. M., Fudal, I., Gu, B., Chen, Q., Affeldt, K. J., Berthier, E., Fischer, G. J., Dou, D., Shan, W., Keller, N. P., Martin, F., Rouxel, T., and Lawrence, C. B. 2013. Microbeindependent entry of oomycete RxLR effectors and fungal RxLR-like effectors into plant and animal cells is specific and reproducible. Mol. Plant-Microbe Interact. 26:611-616.

Upadhyaya, N. M., Mago, R., Staskawicz, B. J., Ayliffe, M. A., Ellis, J. G., and Dodds, P. N. 2014. A bacterial type III secretion assay for delivery of fungal effector proteins into wheat. Mol. Plant-Microbe Interact. 27:255-264.
Vallee, B. L., and Auld, D. S. 1990. Active-site zinc ligands and activated $\mathrm{H} 2 \mathrm{O}$ of zinc enzymes. Proc. Natl. Acad. Sci. U.S.A. 87: 220-224.

Wolfinger, R. D., Gibson, G., Wolfinger, E. D., Bennett, L., Hamadeh, H., Bushel, P., Afshari, C., and Paules, R. S. 2001. Assessing gene significance from cDNA microarray expression data via mixed models. J. Comput. Biol. 8:625-637.

Zhang, J., Li, W., Xiang, T., Liu, Z., Laluk, K., Ding, X., Zou, Y., Gao, M., Zhang, X., Chen, S., Mengiste, T., Zhang, Y., and Zhou, J. M. 2010. Receptor-like cytoplasmic kinases integrate signaling from multiple plant immune receptors and are targeted by a Pseudomonas syringae effector. Cell Host Microbe 7:290-301.

Zhang, W.-J., Pedersen, C., Kwaaitaal, M., Gregersen, P. L., Mørch, S. M., Hanisch, S., Kristensen, A., Fuglsang, A. T., Collinge, D. B., and Thordal-Christensen, H. 2012. Interaction of barley powdery mildew effector candidate CSEP0055 with the defence protein PR17c. Mol. Plant Pathol. 13:1110-1119.

\section{AUTHOR-RECOMMENDED INTERNET RESOURCES}

Broad Institute website: http://www.broadinstitute.org EMBL-EBI Pfam database: http://pfam.janelia.org/family/PF13933 GitHub LeafQuant programs repository: http://git.io/leafquant OrthoMCL database: http://www.orthomcl.org/orthomcl Plant Expression database (PLEXdb): www.plexdb.org 